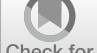

Check for

updates

Cite as

Nano-Micro Lett.

(2021) $13: 181$

Received: 10 June 2021

Accepted: 22 July 2021

Published online: 18 August 2021

(C) The Author(s) 2021

\section{Structural Design Strategies of Polymer Matrix Composites for Electromagnetic Interference Shielding: A Review}

\author{
Chaobo Liang ${ }^{1,2}$, Zhoujie Gu ${ }^{3}$, Yali Zhang ${ }^{2}$, Zhonglei Ma ${ }^{2} \bowtie$, Hua Qiu², Junwei Gu${ }^{2} \bowtie$
}

\title{
HIGHLIGHTS
}

- The review discusses the key concepts, loss mechanisms and test methods of electromagnetic interference (EMI) shielding.

- The research progress of polymer matrix EMI shielding composites with different structures is detailedly illustrated, especially their preparation methods and corresponding evaluations.

- The key scientific and technical problems for polymer matrix EMI shielding composites with different structures are proposed, and their development trend are prospected.

ABSTRACT With the widespread application of electronic communication technology, the resulting electromagnetic radiation pollution has been significantly increased. Metal matrix electromagnetic interference (EMI) shielding materials have disadvantages such as high density, easy corrosion, difficult processing and high price, etc. Polymer matrix EMI shielding composites possess light weight, corrosion resistance and easy processing. However, the current polymer matrix composites present relatively low electrical conductivity and poor EMI shielding performance. This review firstly discusses the key concept, loss mechanism and test method of EMI shielding. Then the current development status of EMI shielding materials is summarized, and the research progress of polymer matrix EMI shielding composites with different structures is illustrated, especially for their preparation methods and evaluation. Finally, the corresponding key scientific and technical problems are proposed, and their development trend is also prospected.

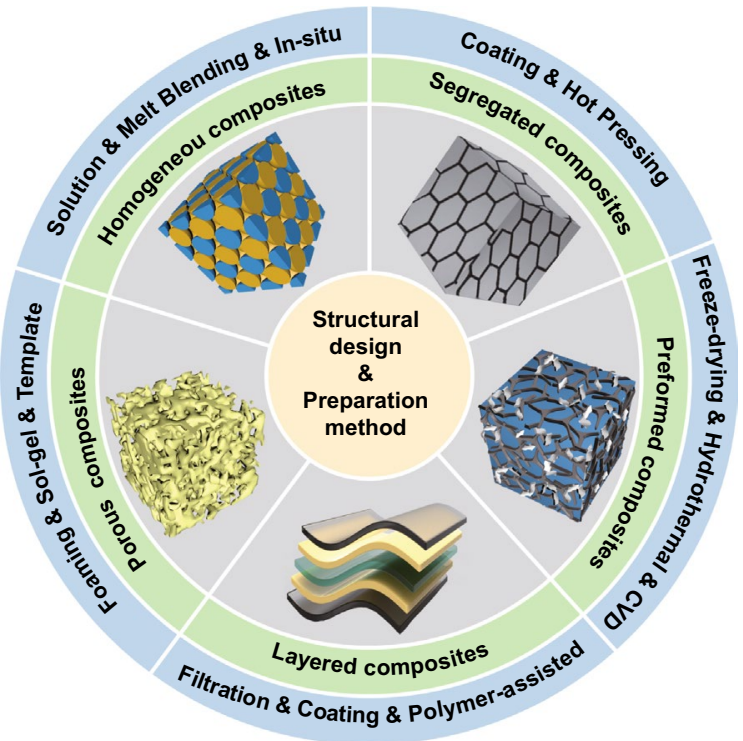

KEYWORDS Polymer matrix composites; Electromagnetic interference shielding; Structural design

Chaobo Liang and Zhoujie Gu contributed equally to this work and should be considered as co-first authors.

$\bowtie$ Zhonglei Ma, mazl@nwpu.edu.cn; Junwei Gu, gjw@nwpu.edu.cn; nwpugjw@163.com

1 Key Laboratory of Functional Nanocomposites of Shanxi Province, College of Materials Science and Engineering, North University of China, Taiyuan 030051, China

2 Shaanxi Key Laboratory of Macromolecular Science and Technology, School of Chemistry and Chemical Engineering, Northwestern Polytechnical University, Xian 710072, China

3 Research and Development Center, Guangdong Suqun New Materials Co., Ltd, Dongguan 523000, China 


\section{Introduction}

With the rapid development of 5G technology, artificial intelligence, Internet of Things, big data and their wide applications in unmanned systems, high-speed communications, industrial internet, future energy, aerospace and other fields, the development level of information technology has become a reflection of the comprehensive national power. However, the electronic devices can generate undesirable electromagnetic interference (EMI) to the outside world during operation, which not only affects the normal operation of nearby electronic devices, but also increases the risk of related workers suffering from headaches, depression, immune deficiency, and other diseases [1-3]. Therefore, there is an urgent need for high-efficiency EMI shielding materials to attenuate electromagnetic waves to protect the normal operation of electronic equipment and human health. In this context, devoting to the development of various highperformance EMI shielding materials has become a research hotspot [4-6].

Polymer matrix composites have been widely used in the field of EMI shielding due to their low density, corrosion resistance, competitive prices and good processability [7, 8]. However, most of the polymer matrix is inherently insulating, which severely limits the applications in electronic products, new energy vehicles, medical equipments, flexible circuit boards and other fields with high EMI shielding requirements $[9,10]$. Currently, researchers have effectively solved the problem of poor EMI shielding performance of polymer matrix composites by compounding conductive fillers with resin matrix. Meanwhile, carbon nanotubes, graphene, metal nanowires/particles, and MXene have been widely used as conductive fillers for polymer matrix composites, and the current status of polymer matrix EMI shielding composites based on different types of conductive fillers has also been outlined and discussed in detail [11-13].

However, the current polymer matrix composites have disadvantages such as low electrical conductivity and poor EMI shielding properties compared to the metallic materials. How to improve the EMI shielding performance of polymer matrix composites through efficient structural design has become a technical difficulty and scientific problem that needs to be solved urgently [14]. In addition to the significant influences of the amount and type of conductive fillers on the EMI shielding performance of polymer matrix composites, the structural design of composites and the distribution orientation of the conductive fillers in the resin matrix are equally important. So far, few reviews based on different structural types of polymer matrix EMI shielding composites have been reported. Therefore, a comprehensive overview of the relationship between structure and EMI shielding performance of polymer matrix composites can help identify possible research directions to overcome the bottleneck of the existing technology and promote the further development of polymer matrix composites in the field of EMI shielding.

In view of this, the review first discusses the key concepts, loss mechanisms and test methods of EMI shielding. Then, the current development status of EMI shielding materials is totally summarized, and the research progress of polymer matrix EMI shielding composites with different structures is detailedly illustrated, especially their preparation methods and corresponding evaluations. Finally, the key scientific and technical problems for polymer matrix EMI shielding composites with different structures are proposed, and their development trend is prospected, which is expected to provide some guidance for the design, developments and industrial applications of the high-performance polymer matrix EMI shielding composites.

\section{Overview of EMI Shielding}

At present, the most effective means to eliminate electromagnetic radiation pollution is the implementation of EMI shielding. EMI shielding means that to cut off or attenuate the electromagnetic waves generated by the work of highfrequency circuits to the outside world. This not only eliminates interference to neighboring electronic equipment and radiation to the human body, but also ensures that electronic equipment itself is not affected by external equipment $[15$, 16]. Due to the rapid development of electrical equipment such as satellite communications, radio and television, people have been unable to avoid exposure to a wide range of electromagnetic radiation pollution in most parts of the world [17-19]. 


\subsection{EMI Shielding Classification}

In daily life, the high-precision electronic components and human being are often exposed to different kinds of electromagnetic radiation threats. It is crucial to use effective protection measures to shield electromagnetic radiation. According to the electromagnetic wave interference sources, EMI shielding can be classified as electrostatic field shielding, magnetic field shielding and electromagnetic field shielding.

\subsubsection{Electrostatic Field Shielding}

For the electrostatic field radiation, a conductive cavity can be applied to protect the electromagnetic sensitive equipment (external electric field shielding), as shown in Fig. 1a. Under the effect of an external electrostatic field, the left and right sides of the conductive cavity induce the opposite electric charges with equal intensity. According to the principle of electrostatic balance, the conductive cavity is an equipotential body with the internal potential difference and electric field intensity of zero. Therefore, the electromagnetic sensitive equipment inside the conductive cavity is protected from the interference of the external electrostatic field. In addition, for the electrostatic field radiation, the radiation source can also be shielded by the conductive cavity to protect the electromagnetic sensitive equipment (internal electric field shielding), as shown in Fig. 1 b. Under the effect of the charged body inside the conductive cavity (generating electrostatic field), the inner surface of the cavity induces an equal negative charge opposite to the charged body, while the outer surface of the cavity induces an equal positive charge. As the outer surface is connected to the earth through the ground wire, the positive charge induced on the outer surface and the electric field outside the conductive cavity disappear, thereby realizing the protection of electromagnetic sensitive equipment outside the conductive cavity [5].

\subsubsection{Magnetic Field Shielding}

For the shielding of low-frequency magnetic field, the shielding cavity with low reluctance is used in parallel with the protected space area, and the low-frequency magnetic field always tends to pass through the shielding cavity preferentially to realize the shielding protection of the internal space in the cavity, as shown in Fig. 2a. The higher permeability results in the lower magnetic resistance of the materials. Therefore, iron, cobalt, nickel and their alloys with high magnetic permeability are ideal materials for low-frequency magnetic field shielding. For the shielding of high-frequency magnetic field, the shielding cavity is used to generate an induced current under the external magnetic field, which excites an induced magnetic field opposite to the original magnetic field. As shown in Fig. 2b, the two magnetic fields achieve the shielding of high-frequency magnetic field by canceling each other. The high-frequency current in the coil generates a high-frequency radiating magnetic field, and the induced current in the shielding coil is opposite to that in the coil according to Faraday's law of electromagnetic induction. Therefore, the magnetic fields generated by the two coils are always in opposite directions outside the shielded coil, and the shielding of high-frequency magnetic field is achieved by canceling each other [5]. (a)

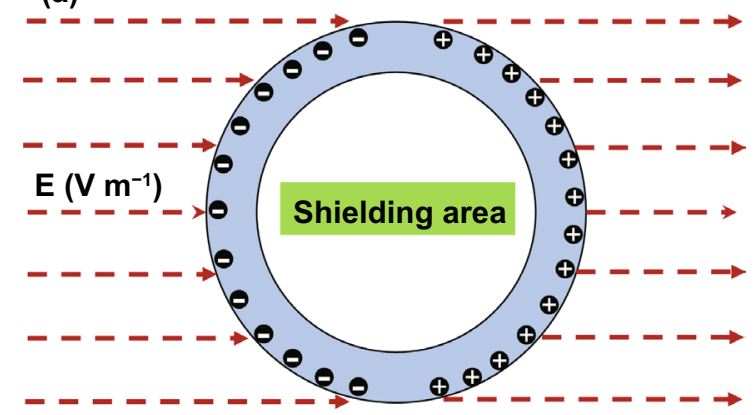

(b)

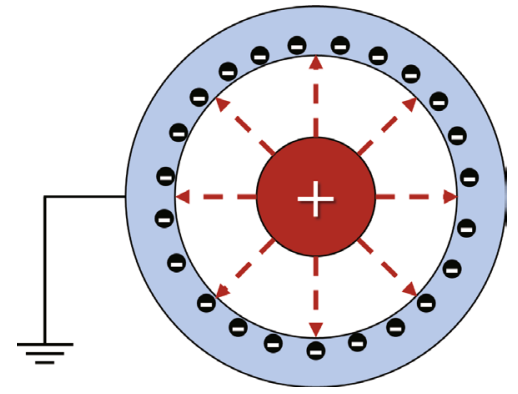

Fig. 1 Schematic diagram of EMI shielding mechanism of a external electric field and $\mathbf{b}$ internal electric field 


\subsubsection{Electromagnetic Field Shielding}

In practical applications, most shielding refers to electromagnetic field shielding. In the alternating electromagnetic field, the shielding of electric and magnetic fields must be considered together as the electric field and magnetic field always exist simultaneously. The electromagnetic radiation can be divided into near-field and far-field radiation depending on the electromagnetic waveform. When the distance between the electromagnetic radiation source and the shielding body is less than $/ 2$ ( is the wavelength of the electromagnetic radiation source), it is defined as the nearfield radiation. There is a phase difference of $90^{\circ}$ between the electric and magnetic fields of electromagnetic waves in the near-field radiation. The energy of the electric and magnetic fields of electromagnetic waves attenuates as the distance between the electromagnetic radiation source and the shield increases. If the electromagnetic radiation source has a large current with low voltage, the electromagnetic radiation source is dominated by a magnetic field. At this time, only the magnetic field shielding should be considered, and the electric field shielding should be ignored. If the electromagnetic radiation source has a small current with high voltage, the electromagnetic radiation source is dominated by an electric field. At this time, only the electric field shielding can be considered, and the magnetic field shielding can be ignored. When the distance between the electromagnetic radiation source and the shielding body is larger than 12 , it is defined as the far-field radiation. The electric and the magnetic fields of the electromagnetic waves in the farfield radiation have the same phase and are perpendicular to each other. Therefore, the electric and magnetic fields of the electromagnetic waves have the same energy, and their shielding cannot be ignored. According to Maxwell's classical electromagnetic theory, the electric and magnetic fields of high-frequency electromagnetic waves are always closely linked together to form a unified electromagnetic field rather than exist in isolation. Therefore, as long as the radiation from the electric or magnetic field is completely shielded, the other radiation will no longer exist in practical applications.

\subsection{Mechanism of EMI Shielding}

In order to understand the EMI shielding more intuitively, various shielding mechanisms have been proposed, such as the eddying effect theory, electromagnetic field theory, and transmission line theory. Among these, the transmission line theory has been most widely recognized [20-22]. The transmission line theory means that the electromagnetic waves passing through the shielding materials will be affected by three different shielding mechanisms, including the reflection, absorption and multiple reflection. Specifically, when the electromagnetic waves are incident on the surface of the shielding materials, the electromagnetic waves are reflected due to the impedance mismatch between the shielding materials and the external free space. The unreflected electromagnetic waves enter the inside of the shielding materials and are continuously attenuated by dielectric loss and magnetic loss. In addition, the electromagnetic waves can be dissipated through multiple reflections at the interface inside the materials. The residual electromagnetic waves will
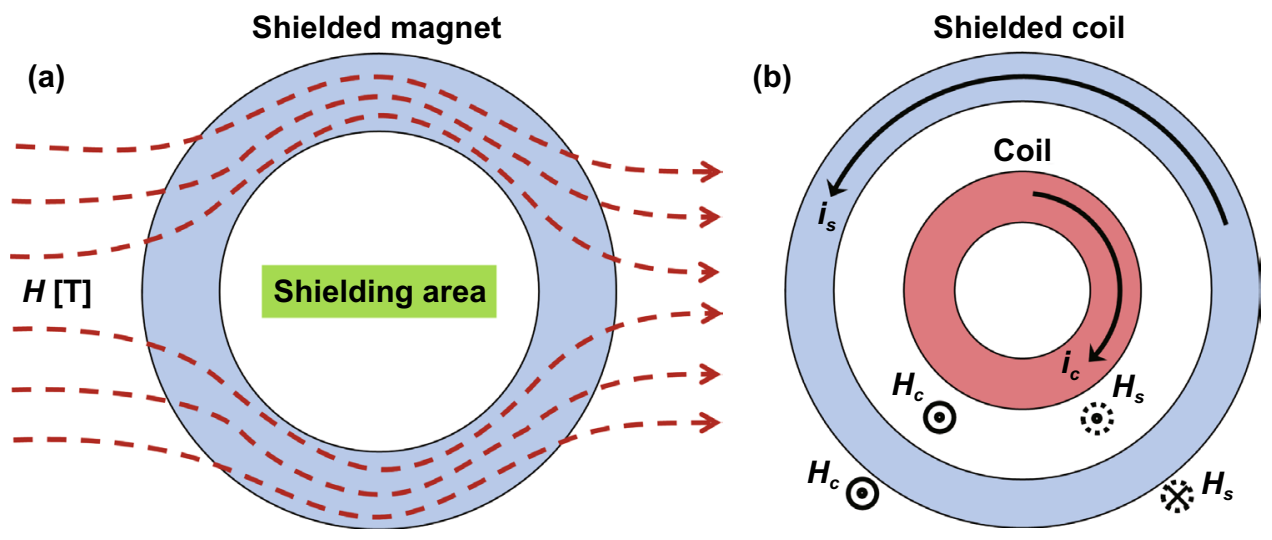

Fig. 2 Schematic diagram of EMI shielding mechanism of a low-frequency magnetic field and $\mathbf{b}$ high-frequency magnetic field 
pass through the shielding materials and become transmitted waves $[11,23]$. The EMI shielding mechanism is shown in Fig. 3.

The attenuation or loss of electromagnetic waves is one of the key indicators for the materials to evaluate the ability of shielding electromagnetic waves. It can qualitatively describe the difference in electromagnetic wave intensity before and after the shielding process. EMI shielding effectiveness (EMI SE, unit: $\mathrm{dB}$ ) can be used to quantitatively evaluate the ability of materials to shield electromagnetic waves. It is defined as the ratio of the electric field strength $(E)$, magnetic field strength $(H)$ or power $(P)$ of the electromagnetic waves before entering the shielding materials and those after passing through the shielding materials, expressed as Eq. 1 [7, 24]:

$\mathrm{SE}=20 \lg \left(\frac{E_{t}}{E_{i}}\right)=20 \lg \left(\frac{H_{t}}{H_{i}}\right)=20 \lg \left(\frac{P_{t}}{P_{i}}\right)$

In Eq. 1, the subscripts $i$ and $t$ represent the incident electromagnetic waves and transmitted electromagnetic waves, respectively. $E_{i}, H_{i}$, and $P_{i}$ represent the incident electric field, magnetic field and power intensity respectively, while $E_{t}, H_{t}$, and $P_{t}$ represent the transmitted electric field, magnetic field, and power intensity, respectively. According to Schelkunoff theory, EMI SE is defined as the sum of three shielding mechanisms including reflection $\left(\mathrm{SE}_{R}\right)$, absorption $\left(\mathrm{SE}_{A}\right)$ and multiple reflections $\left(\mathrm{SE}_{M}\right)$ for attenuation of electromagnetic waves by shielding materials.

$\mathrm{SE}_{T}=\mathrm{SE}_{R}+\mathrm{SE}_{A}+\mathrm{SE}_{M}$

In Eq. 2, $\mathrm{SE}_{R}, \mathrm{SE}_{A}$ and $\mathrm{SE}_{M}$ can be calculated by Eqs. 3-5:

$\mathrm{SE}_{R}=168.2+10 \lg \left(\frac{\sigma_{r}}{f \mu_{r}}\right)$

$\mathrm{SE}_{A}=131.43 t \sqrt{f \mu_{r} \sigma_{r}}$

$\mathrm{SE}_{M}=20 \lg \left(1-e^{\frac{-2 t}{\delta}}\right)=20 \lg \left(1-10^{\frac{\mathrm{SE}_{A}}{10}}\right)$

where, $\sigma_{r}$ is the relative electrical conductivity, $\mu_{r}$ is the relative magnetic permeability, $f$ is the frequency of electromagnetic waves $(\mathrm{Hz}), t$ is the thickness of the shielding materials $(\mathrm{m}), \delta$ is the skin depth $(\mathrm{m})$, and $r$ is the distance from the radiation source to the shielding materials (m). From Eq. 5, $\mathrm{SE}_{M}$ and $\mathrm{SE}_{A}$ are correlated with each other. $\mathrm{SE}_{M}$ plays a crucial role in the geometric morphological structures.

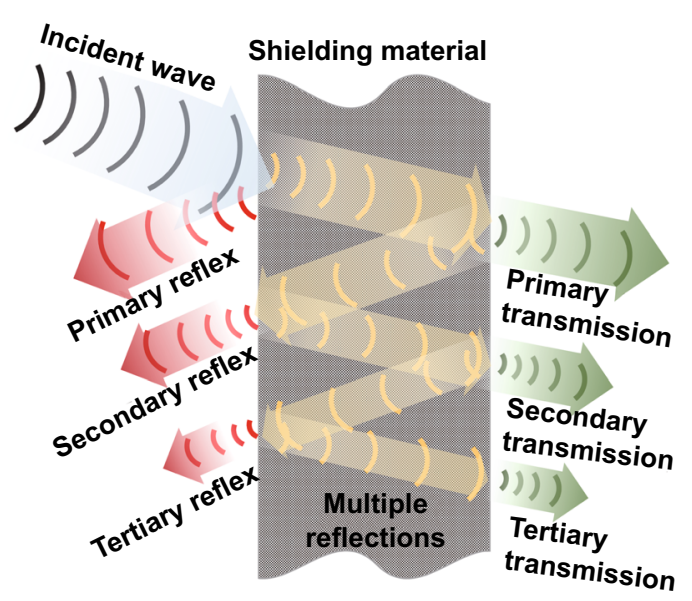

Fig. 3 Schematic diagram of EMI shielding mechanism based on transmission line theory

However, $\mathrm{SE}_{M}$ can be neglected for relatively thick shielding materials, as the amplitude of electromagnetic waves is negligible when they reach the second boundary of the shielding materials. In other words, when the $\mathrm{SE}_{A}$ of the shielding materials is $\geq 10 \mathrm{~dB}$, the $\mathrm{SE}_{M}$ can be neglected [12]. It can also be seen from the equation that $\mathrm{SE}_{R}$ is inversely related to $f$ and $\mu_{r}$, and positively related to $\sigma_{r} . \mathrm{SE}_{A}$ is positively related to the $t, f, \mu_{r}$, and $\sigma_{r}$ of the shielding materials. Therefore, the increase of magnetic properties can improve the $\mathrm{SE}_{A}$ and reduce the $\mathrm{SE}_{R}$ of the shielding materials. The increase of electrical conductivity can simultaneously improve $\mathrm{SE}_{R}$ and $\mathrm{SE}_{A}$ of the shielding materials, thereby enhancing their EMI shielding performances $[25,26]$.

\subsection{Test Methods for EMI Shielding}

For the tests of EMI SE in the near-field and far-field radiation, the researchers developed the corresponding shielded room method and the network analyzer method, as shown in Fig. 4a, b respectively. The shielded room method is a common technique used for the near-field EMI SE measurement. The test process is as follows: A specific test window is opened on the wall of a shielded room made of metal plates, and electromagnetic wave transmitters and electromagnetic wave receivers are placed on opposite sides of the test window, respectively. The signal intensity of the electromagnetic waves with the test window free of the materials (electric field strength $E_{0}$, magnetic field strength $H_{0}$ or power $\left.P_{0}\right)$ and the signal intensity of the electromagnetic waves with the test window covered by the materials (electric field 
strength $E_{1}$, magnetic field strength $H_{1}$ or power $P_{1}$ ) are both tested. Thereby, the ratio of the two kind of received signal intensity is used as the EMI SE of the test materials, as shown in Eq. 6 [2]:

$\mathrm{SE}=20 \lg \left(\frac{E_{0}}{E_{1}}\right)=20 \lg \left(\frac{H_{0}}{H_{1}}\right)=20 \lg \left(\frac{P_{0}}{P_{1}}\right)$

The network analyzer method is a common technique used for the far-field EMI SE measurement. The EMI SE in the far field can be calculated by the measured $S$-parameters $\left(S_{11}, S_{21}, S_{22}, S_{12}\right)$ from a vector network analyzer, where $S_{i j}$ indicates the transmission from port $j$ to port $i$. Based on the $S$-parameters, the reflectance $(R)$, absorbance $(A)$ and transmittance $(T)$ can be calculated by Eqs. 7, 8, and 9 , respectively [3]:

$R=\left|S_{11}\right|^{2}=\left|S_{22}\right|^{2}$

$T=\left|S_{12}\right|^{2}=\left|S_{21}\right|^{2}$

$A=1-R-T$

$\mathrm{SE}_{T}, \mathrm{SE}_{R}$ and $\mathrm{SE}_{A}$ can be obtained by calculating $R, A$ and $T$ as shown in Eqs. 10, 11, and 12, respectively:

$$
\begin{aligned}
& \mathrm{SE}_{T}=10 \lg \left(\frac{1}{T}\right)=10 \lg \left(\frac{1}{\left|S_{12}\right|^{2}}\right) \\
& \mathrm{SE}_{R}=10 \lg \left(\frac{1}{1-R}\right)=10 \lg \left(\frac{1}{1-\left|S_{11}\right|^{2}}\right)
\end{aligned}
$$

$\mathrm{SE}_{A}=10 \lg \left(\frac{1-R}{T}\right)=10 \lg \left(\frac{1-\left|S_{11}\right|^{2}}{\left|S_{12}\right|^{2}}\right)$

\section{Classification of EMI Shielding Materials}

The shielding technology plays a vital role in controlling or reducing the electromagnetic radiation pollution, among which high-performance EMI shielding materials are the key to the realization of shielding technology [27, 28]. According to the EMI SE values, EMI shielding materials can be divided into various categories: (a) low-level shielding materials $(10-30 \mathrm{~dB})$, which can be used in low-end shielding applications; (b) medium-level shielding materials (30-60 dB), which can meet most industrial-grade shielding needs; (c) high-level shielding materials (60-90 dB), which can meet the shielding needs of the military industry and aerospace fields; (d) high-precision shielding materials ( $>90 \mathrm{~dB}$ ), which can meet the shielding needs of highprecision and high-sensitive precision electronic devices $[11,29]$. According to the matrix, EMI shielding materials can be divided into metallic EMI shielding materials, magnetic EMI shielding materials and conductive polymer EMI shielding materials. In order to obtain a more comprehensive understanding of EMI shielding materials, this section provides a brief classification and overview of current EMI shielding materials. (a)

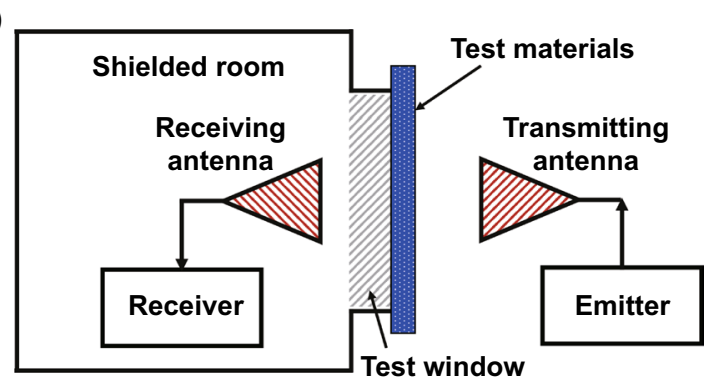

(b) Vector network

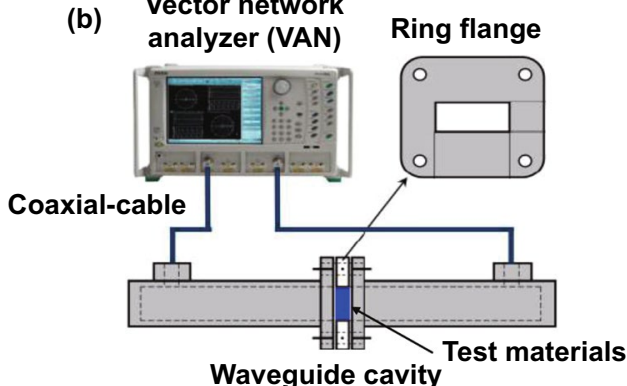

Fig. 4 Schematic diagram of the test principle of a shielded room method and $\mathbf{b}$ network analyzer method 


\subsection{Metallic EMI Shielding Materials}

Conventional metallic materials (e.g., metal sheets, metal blocks, and metal foams, etc.) have been widely used in the field of EMI shielding due to their high electrical conductivity [30-32]. Park et al. [33] prepared the $\mathrm{NiFe} / \mathrm{Cu}$ multilayer sheets by a DC magnetron sputtering technology. The results show that the $4 \mu \mathrm{m}$ thick $\mathrm{NiFe} / \mathrm{Cu}$ multilayer sheets have a batter EMI SE of $90 \mathrm{~dB}$ compared with the single-component $\mathrm{Cu}$ or NiFe sheets in the frequency range of $0.7-10 \mathrm{GHz}$, owing to the multiple reflections of electromagnetic waves between the interfaces of $\mathrm{NiFe} / \mathrm{Cu}$ multilayer sheets. Sambyal et al. [34] synthesized the FeSiAl sendust/metal hybrid materials with magnetic cores and highly conductive metal shells by electroless plating $\mathrm{Ag}$ or Ni metal on the surface of $\mathrm{FeSiAl}$ sendust. The results show that the $\mathrm{FeSiAl}$ sendust coated with $\mathrm{Ag}$ and $\mathrm{Cu}$ exhibits an absorption-dominated EMI SE of 65 and $58 \mathrm{~dB}$, respectively, in the frequency range of $300 \mathrm{kHz}-10 \mathrm{GHz}$. Song et al. [35] used the coaxial cable method to fabricate the EMI SE of AZ31 sheets (Mg-3 wt\% Al-1 wt\% Zn) with different texture strengths. The results show that the EMI SE of the AZ31 sheets reaches 72-98 dB in the frequency band of 30-1500 MHz. Although the metal materials exhibit ultra-high EMI shielding performance, their shallow skin depth leads to the high reflectivity of electromagnetic waves, causing the secondary radiation pollution in the environment. In addition, the metal materials have disadvantages such as high density, expensive, easy to corrode and difficult to process, which greatly limit their wider applications. Moreover, the metal materials usually show magnetic and wave leakages at the joints, which will seriously affect their EMI SE [36-38].

\subsection{Magnetic EMI Shielding Materials}

According to the classical electromagnetic theory, the magnetic materials can shield the electromagnetic waves mainly through the hysteresis loss, eddy current loss, domain wall resonance, ferromagnetic resonance, and natural resonance mechanisms $[39,40]$. Common magnetic shielding materials are mainly divided into two categories: the metal alloy materials based on iron, cobalt, nickel, etc., and the metal oxide materials such as carbonyl iron, carbonyl nickel, ferrite, and garnet [41, 42]. Fei et al. [43] prepared the zeolitic imidazolate framework-67/cellulose nanofiber (ZIF-67/ $\mathrm{CNF}$ ) aerogel via the directional freeze-casting technique, and then obtained magnetic $\mathrm{Co} / \mathrm{C} @ \mathrm{CNF}$ aerogel by the hightemperature thermal reduction. The results show that the EMI SE of the magnetic Co/C@CNF aerogel after thermal reduction at $900{ }^{\circ} \mathrm{C}$ reaches $35 \mathrm{~dB}$. Ren et al. [44] prepared the graphene nanosheets/carbonyl iron-nickel alloy/cyanate ester (GNSs/CINAP/CE) composites by the combination of solution blending and hot pressing. The results show that the EMI SE of the GNSs/CINAP/CE composite reaches $55 \mathrm{~dB}$ when the contents of CINAP and GNSs are $20 \mathrm{wt} \%$ and 5 wt $\%$, respectively. Luo et al. [45] used the electroless plating and spraying techniques to coat silver (Ag) nanoparticles, ferroferric oxide $\left(\mathrm{Fe}_{3} \mathrm{O}_{4}\right)$ nanoparticles and polydimethylsiloxane (PDMS) on the surface of polypropylene (PP) fabrics. The EMI SE of the obtained PP@ $\mathrm{Ag} @ \mathrm{Fe}_{3} \mathrm{O}_{4} @$ PDMS fabric reaches $56 \mathrm{~dB}$. The magnetic metal materials generally have high magnetic permeability and strong saturation magnetization, and are suitable for the radiation shielding in the field of high-frequency weak electric field or low-frequency magnetic field. In addition, among many loss mechanisms, only natural resonance loss can dissipate electromagnetic waves in the GHz band. Thus, the magnetic materials have some limitations in practical applications, so they are usually used in combination with conductive materials [46-48].

\subsection{Conductive Polymer EMI Shielding Materials}

Compared with the traditional metal materials, the conductive polymer materials developed in recent years have become more promising alternatives for EMI shielding due to their high specific strength, corrosion resistance, low cost, and easy processing [49-51]. Depending on the conductive mechanism, the conductive polymer materials used for EMI shielding can be divided into two categories: One is the intrinsic conductive polymer materials, and the other is the composite conductive polymer materials [52-54].

\subsubsection{Intrinsic Conductive Polymer Materials}

The matrix polymer of intrinsic conductive polymer materials possesses conductive ability, such as polypyrrole (PPy), polyaniline (PANI) and polythiophene (POT) [55]. Qiu et al. [56] prepared PANI doped with hydrochloric 
acid (PANI-HCl), PANI doped with camphorsulfonic acid (PANI-CSA), and PANI doped with phosphoric acid (PANI$\mathrm{H}_{3} \mathrm{PO}_{4}$ ). It is noted that the PANI-CSA exhibited the highest $\sigma$ and EMI SE of $1.28 \mathrm{~S} \mathrm{~cm}^{-1}$ and $21 \mathrm{~dB}$, respectively, owing to the more complete oxidation, higher crystallinity and larger crystal size. Muller et al. [57] prepared poly-3, 4-ethylenedioxythiophene/bacterial cellulose nanofiber composite films by in-situ chemical oxidation method, with the $\sigma$ up to $1.5 \mathrm{~S} \mathrm{~cm}^{-1}$. Currently, the conductivity of intrinsic conductive polymer materials is relatively low, and the preparation process is complicated. The process often requires the introduction of some high-cost and corrosive dopants through chemical methods. Moreover, the modified conductive polymer materials generally have the disadvantages of poor stability, high rigidity and difficulty in melt, thus leading to the difficulties in the later processing and molding processes [58-60].

\subsubsection{Filled Conductive Polymer Composites}

The filled conductive polymer composites refer to multiphase composite system with conductive/EMI shielding functions prepared by compounding the polymer matrix with conductive fillers. The filled conductive polymer composites can be used as polymer matrix EMI shielding composites. The commonly used polymer matrixes include polyvinyl alcohol (PVA), polyethylene (PE), polylactic acid (PLA), polyurethane (PU), etc. [61-63]. The conductive fillers are mainly divided into three categories: carbon-based fillers such as graphite, reduced graphene oxide (rGO), multiwalled carbon nanotubes (MWCNTs), carbon black (CB), metalbased fillers such as silver nanowires (AgNWs), copper nanosheets (CuNSs), aluminum powder, composite fillers such as transition metal carbon/nitride grafted with ferric oxide (MXene @ $\mathrm{Fe}_{2} \mathrm{O}_{3}$ ), graphene grafted with ferroferric oxide ( $\mathrm{rGO} @ \mathrm{Fe}_{3} \mathrm{O}_{4}$ ), silver-plated carbon fiber [64-66]. Liang et al. [67] prepared the graphene/epoxy composites by doping functionalized graphene into epoxy resin matrix by a solution blending method. The results show that the graphene/epoxy composite shows a $\sigma$ of $0.1 \mathrm{~S} \mathrm{~cm}^{-1}$ and an EMI SE of $21 \mathrm{~dB}$ when the content of graphene is 15 $w t \%$. Li et al. [68] embedded a copper-plated graphene fiber mesh into the PDMS film, and the results showed that the $\sigma$ and EMI SE of PDMS film reached $3.21 \times 10^{5} \mathrm{~S} \mathrm{~m}^{-1}$ and $74 \mathrm{~dB}$, respectively. Gu et al. [69] prepared the silver nanowire $(\mathrm{AgNW}) / \mathrm{CNF}$ composite film by the combination of vacuum-assisted filtration and hot pressing. The results show that the AgNW/CNF composite film shows a high $\sigma$ of $5.57 \times 10^{5} \mathrm{~S} \mathrm{~m}^{-1}$ and an excellent EMI SE of $101 \mathrm{~dB}$ when the content of AgNWs is $50 \mathrm{wt} \%$. Compared with the intrinsic conductive polymer materials, the composite conductive polymer materials (or polymer matrix EMI shielding composites) have been widely used in many fields such as aerospace, energy transportation, sporting goods, construction facilities, and defense industry thanks to their high strength, easy processing, good flexibility and low production cost, etc. [70-72].

\section{Research Progress of Polymer Matrix EMI Shielding Composites with Different Structural Designs}

The preparation methods have great effects on the distribution of fillers and the microstructures, thereby influencing the overall performance of polymer matrix EMI shielding composites. Table 1 summarizes the EMI shielding performance of polymer matrix composites with different structural types. It can be seen that the structure, density and thickness play a decisive role in the EMI shielding performance of the composites. Therefore, it is crucial to use a suitable preparation method to fabricate the polymer matrix EMI shielding composites that can meet the practical application requirements. Depending on the different structural designs, polymer matrix EMI shielding composites can be classified into homogeneous structure, segregated structure, porous structure, layered structure and preformed structure.

\subsection{Homogeneous Polymer Matrix EMI Shielding Composites}

The homogeneous polymer matrix EMI shielding composites are prepared by the uniform compounding of polymer matrix and conductive fillers through solution blending, melt blending and in-situ polymerization methods. The homogeneous polymer matrix EMI shielding composites have been widely used in practical industrial production due to their simple preparation process [73, 74]. 
Table 1 Comparison of EMI shielding performances of the polymer matrix composites with different structures

\begin{tabular}{|c|c|c|c|c|c|c|c|c|c|}
\hline Type & Materials & $\begin{array}{l}\text { Thickness } \\
(\mathrm{mm})\end{array}$ & EMI SE (dB) & $\begin{array}{l}\text { Frequency } \\
(\mathrm{GHz})\end{array}$ & $\begin{array}{l}\text { Density }(\mathrm{g} \\
\left.\mathrm{cm}^{-3}\right)\end{array}$ & $\begin{array}{l}\text { SSE }\left(d B c^{3}\right. \\
\left.\mathrm{g}^{-1}\right)\end{array}$ & $\begin{array}{l}\mathrm{SE} / \mathrm{t}(\mathrm{dB} \\
\left.\mathrm{cm}^{-1}\right)\end{array}$ & $\begin{array}{l}\mathrm{SSE} / \mathrm{t}(\mathrm{dB} \\
\left.\mathrm{cm}^{2} \mathrm{~g}^{-1}\right)\end{array}$ & Refs \\
\hline \multirow[t]{10}{*}{$\begin{array}{l}\text { Homogene- } \\
\text { ous polymer } \\
\text { composites }\end{array}$} & $\begin{array}{l}\text { GnPs@PDA- } \\
\text { MWCNTs/ } \\
\text { PPSU }\end{array}$ & 3 & 62 & $8-12$ & I & / & 207 & / & [75] \\
\hline & $\begin{array}{l}\text { nAg-MWC- } \\
\text { NTs/NBR }\end{array}$ & 0.02 & 45 & $0.030-1.5$ & I & / & 225 & / & [76] \\
\hline & $\mathrm{ABS} / \mathrm{CB}$ & 1.1 & 21 & $8.2-12.4$ & / & / & 190 & / & [77] \\
\hline & $\mathrm{ABS} / \mathrm{CF}$ & 1.1 & 35 & $8.2-12.4$ & / & / & 318 & / & [77] \\
\hline & $\begin{array}{l}\text { ABS/MWC- } \\
\text { NTs }\end{array}$ & 1.1 & 51 & $8.2-12.4$ & I & I & 464 & / & [77] \\
\hline & $\begin{array}{l}\text { MWCNTs/ } \\
\text { PVDF }\end{array}$ & 2 & 56 & $8-12$ & 0.79 & 71 & 280 & 354 & [80] \\
\hline & SCF/EVA & 3.5 & 34 & $8-12$ & / & / & 97 & / & [81] \\
\hline & $\begin{array}{l}\text { PP/EPDM/ } \\
\text { NCGF }\end{array}$ & 2 & 41 & $8.2-12.4$ & / & I & 205 & / & {$[82]$} \\
\hline & $\begin{array}{c}\text { PPy/PDA/ } \\
\text { AgNW }\end{array}$ & / & 48 & $8-12$ & 0.28 & 171 & / & 611 & [85] \\
\hline & $\begin{array}{l}\text { PANI-MWC- } \\
\text { NTs }\end{array}$ & 2 & 39 & $12.4-18.0$ & / & I & 195 & / & [86] \\
\hline \multirow{4}{*}{$\begin{array}{l}\text { Segregated } \\
\text { polymer } \\
\text { composites }\end{array}$} & graphite/PE & 1 & 26 & $26-37.5$ & I & I & 260 & I & [94] \\
\hline & $\begin{array}{l}\text { CB/UHM- } \\
\text { WPE }\end{array}$ & 2.1 & 33 & $8.2-12.4$ & I & / & 157 & I & [95] \\
\hline & rGO/PS & 2.5 & 45 & $8.2-12.4$ & / & I & 180 & / & [96] \\
\hline & MXene@PS & 2 & 62 & $8.2-12.4$ & / & / & 310 & I & [97] \\
\hline \multirow{10}{*}{$\begin{array}{l}\text { Porous } \\
\text { polymer } \\
\text { composites }\end{array}$} & f-G/PVDF & / & 20 & $8-12$ & I & / & I & I & [105] \\
\hline & $\begin{array}{l}\text { PMMA/ } \\
\text { GNPs- } \\
\text { MWCNTs }\end{array}$ & 2.5 & 36 & $8-12$ & 0.6 & 60 & 144 & 240 & [106] \\
\hline & AgNS/epoxy & 2 & 42 & $8-12$ & 0.172 & 244 & 210 & 1221 & [107] \\
\hline & $\begin{array}{l}\text { MWCNTs/ } \\
\text { WPU }\end{array}$ & 2.3 & 50 & $8.2-12.4$ & 0.126 & 397 & 217 & 1722 & [109] \\
\hline & RGO/LDC & 2 & 49 & $8.2-12.4$ & 0.008 & 6125 & 245 & 30,625 & [110] \\
\hline & $\mathrm{AgNW} / \mathrm{CNF}$ & 2 & 40 & $8.2-12.4$ & 0.0017 & 23,888 & 200 & 178,235 & [111] \\
\hline & MXene/CNF & 2 & 35 & $8.2-12.4$ & 0.0015 & 23,633 & 175 & 118,167 & [112] \\
\hline & $\begin{array}{l}\mathrm{AgNW} / \mathrm{PVB} / \\
\mathrm{MS}\end{array}$ & 5 & 60 & $8-12$ & 0.0019 & 31,579 & 120 & 63,158 & [116] \\
\hline & $\begin{array}{l}\mathrm{Fe}_{3} \mathrm{O}_{4} @ \\
\quad \mathrm{MXene} / \mathrm{GF} / \\
\text { PDMS }\end{array}$ & 1 & 80 & $8.2-12.4$ & I & I & 800 & / & [117] \\
\hline & $\begin{array}{l}\text { PU@PDA@ } \\
\text { Ag }\end{array}$ & 5 & 84 & $8.2-12.4$ & 0.032 & 2625 & 168 & 5250 & [118] \\
\hline \multirow[t]{3}{*}{$\begin{array}{l}\text { Layered } \\
\text { polymer } \\
\text { composites }\end{array}$} & $\begin{array}{l}\text { ANF- } \\
\text { MXene/ } \\
\text { AgNW }\end{array}$ & 0.091 & 80 & $8.2-12.4$ & 1.63 & 8769 & 8791 & 5379 & [124] \\
\hline & $\begin{array}{l}\text { CNF@ } \\
\text { MXene }\end{array}$ & 0.035 & 40 & $8.2-12.4$ & 1.62 & 25 & 11,429 & 7029 & [125] \\
\hline & $\begin{array}{l}\text { MXene/c- } \\
\text { PANI }\end{array}$ & 0.04 & 36 & $8.2-12.4$ & / & I & 9000 & / & [126] \\
\hline
\end{tabular}


Table 1 (continued)

\begin{tabular}{|c|c|c|c|c|c|c|c|c|c|}
\hline Type & Materials & $\begin{array}{l}\text { Thickness } \\
(\mathrm{mm})\end{array}$ & EMI SE (dB) & $\begin{array}{l}\text { Frequency } \\
(\mathrm{GHz})\end{array}$ & $\begin{array}{l}\text { Density }(\mathrm{g} \\
\left.\mathrm{cm}^{-3}\right)\end{array}$ & $\begin{array}{l}\mathrm{SSE}\left(\mathrm{dB} \mathrm{cm} \mathrm{cm}^{3}\right. \\
\left.\mathrm{g}^{-1}\right)\end{array}$ & $\begin{array}{l}\mathrm{SE} / \mathrm{t}(\mathrm{dB} \\
\left.\mathrm{cm}^{-1}\right)\end{array}$ & $\begin{array}{l}\mathrm{SSE} / \mathrm{t}(\mathrm{dB} \\
\left.\mathrm{cm}^{2} \mathrm{~g}^{-1}\right)\end{array}$ & Refs \\
\hline & $\begin{array}{c}\mathrm{Fe}_{3} \mathrm{O}_{4} @ \mathrm{rGO} / \\
\text { MWCNTs/ } \\
\text { WPU }\end{array}$ & 0.8 & 35.9 & $8.2-12.4$ & I & / & 449 & I & {$[40]$} \\
\hline & PVA/MXene & 0.027 & 44.4 & $8.2-12.4$ & 1.76 & 25 & 16,444 & 9343 & [129] \\
\hline & $\begin{array}{l}\mathrm{Ag} / \mathrm{NWF} / \\
\text { FeCo@ } \\
\text { rGO/WPU }\end{array}$ & 0.4 & 77 & $2-18$ & / & / & 1925 & / & [130] \\
\hline & $\begin{array}{l}\mathrm{Fe}_{3} \mathrm{O}_{4} @ \\
\mathrm{rGO} / \mathrm{T}- \\
\mathrm{ZnO} / \mathrm{Ag} / \\
\text { WPU }\end{array}$ & 0.5 & 87 & $8.2-12.4$ & I & I & 1740 & l & [131] \\
\hline & $\begin{array}{l}\mathrm{Cu}-\mathrm{Ag} / \mathrm{ITO} / \\
\mathrm{PET}\end{array}$ & 0.05 & 26 & $8-40$ & I & / & 5200 & I & [137] \\
\hline & $\begin{array}{l}\text { AgNW/PVA/ } \\
\text { PET }\end{array}$ & I & 44 & $8.2-12.4$ & / & I & I & I & [138] \\
\hline & $\begin{array}{r}\text { AgNW/ } \\
\text { PDDA }\end{array}$ & / & 31 & $8-12$ & I & I & I & I & [139] \\
\hline & $\begin{array}{l}\text { AgNW/ } \\
\text { MXene/ } \\
\text { PET }\end{array}$ & / & 49 & $8.2-12.4$ & I & I & I & I & [140] \\
\hline \multirow{5}{*}{$\begin{array}{l}\text { Preformed } \\
\text { polymer } \\
\text { composites }\end{array}$} & $\begin{array}{l}\text { Graphene/ } \\
\text { PDMS }\end{array}$ & 5 & 42 & $8.2-12.4$ & I & I & 84 & I & [146] \\
\hline & $\begin{array}{l}\mathrm{GF} / \mathrm{h}-\mathrm{Fe}_{3} \mathrm{O}_{4} / \\
\text { PDMS }\end{array}$ & 2 & 70 & $8.2-12.4$ & 1.179 & 59 & 350 & 297 & [147] \\
\hline & $\begin{array}{l}\text { Epoxy/wood- } \\
\text { derived } \\
\text { carbon }\end{array}$ & 2 & 27.8 & $8-12$ & 1.17 & 24 & 139 & 119 & [148] \\
\hline & $\begin{array}{c}\mathrm{Fe}_{3} \mathrm{O}_{4} / \\
\text { TAGA/ } \\
\text { epoxy }\end{array}$ & 3 & 35 & $8.2-12.4$ & I & I & 117 & I & [149] \\
\hline & TCTA/ероху & 2 & 74 & $8.2-12.4$ & 1.2 & 62 & 370 & 308 & [150] \\
\hline
\end{tabular}

\subsubsection{Solution Blending Method}

The solution blending method refers to fabricating the polymer matrix EMI shielding composites by dispersing the conductive fillers in the polymer matrix using a suitable solvent and then removing the solvent. In the solution mixing system with lower viscosity, the polymer and the conductive fillers can be uniformly mixed to ensure the formation of conductive pathways inside the final composites. He et al. [75] dissolved the polydopamine-modified graphite nanosheets (GnPs@PDA), MWCNTs and polyphenylsulfone (PPSU) in N, N-dimethylformamide (DMF), and then the GnPs@ PDA-MWCNTs/PPSU composite powder was obtained by flocculation under an ice-water bath. Finally, the GnPs@ PDA-MWCNTs/PPSU composites were obtained after hot pressing. The results show that the EMI SE of the composites reaches $62 \mathrm{~dB}$ when the content of GnPs@PDAMWCNTs is 17.6 vol\%. Kwon et al. [76] first dissolved the nitrile butadiene rubber (NBR) and MWCNTs grafted with silver nanoparticles (nAg-MWCNTs) in a toluene solvent, and then completely removed the toluene solvent with continuous stirring. Finally, the nAg-MWCNTs/NBR composites were obtained after curing (Fig. 5a). The results show that the EMI SE of the nAg-MWCNTs/NBR composites reaches $45 \mathrm{~dB}$ when the content of nAg-MWCNTs is 83 wt\%. Al-Saleh et al. [77] fabricated the ABS/CB, ABS/carbon nanofibers (CF), and ABS/MWCNTs composites via the similar method. When the contents of the three fillers is 15 $\mathrm{wt} \%$, the $\mathrm{ABS} / \mathrm{CB}, \mathrm{ABS} / \mathrm{CF}$ and $\mathrm{ABS} / \mathrm{MWCNTs}$ composites exhibit EMI SE values of 21, 35, and $51 \mathrm{~dB}$, respectively. 
The solution blending method can significantly reduce the viscosity of the composite system, thereby improving the dispersion of the fillers in the polymer matrix. However, the method also has significant disadvantages such as the needs to add a large amount of solvent during the preparation process. Many polymer materials can only swell but not dissolve in the solvent, and the incomplete subsequent treatment of the solvent can shorten the service life of the materials. Moreover, the removal of the solvent will bring the environmental problem and cost concern. Therefore, the industrial large-scale production of the solution blending method still needs further exploration [78, 79].

\subsubsection{Melt Blending Method}

The melt blending method refers to the homogeneous mixing of the molten polymer and conductive fillers by a mixing equipment above the viscous flow temperature of the polymer matrix, after cooling, the polymer matrix EMI shielding composites are obtained. Compared with the solution blending method, the melt blending method has simple operation, low cost, and no third-party solvent. The method has a wide range of industrial applications, and most of the thermoplastic EMI shielding composites can be prepared by this method. Wang et al. [80] used MWCNTs as conductive filler and polyvinylidene fluoride (PVDF) as matrix to prepare the MWCNTs/PVDF composites through the melt blending and compression molding. The results show that the EMI SE of the MWCNTs/PVDF composites reaches $56 \mathrm{~dB}$ when the MWCNT content is $15 \mathrm{wt} \%$. Das et al. [81] used short carbon fiber (SCF) as conductive filler, natural rubber (NR) and ethylene-vinyl acetate copolymer (EVA) as matrix, and fabricated the SCF/NR and SCF/EVA composites by the similar method. When the content of SCF is 17.5 wt $\%$, the SCF/NR composites exhibit an EMI SE of $20 \mathrm{~dB}$. However, the EMI SE of SCF/EVA composites reaches the same level with only $8 \mathrm{wt} \%$ of SCF owing to the low viscosity of EVA. Duan et al. [82] used nickel-coated glass fiber (NCGF) as the conductive filler, polypropylene (PP) and

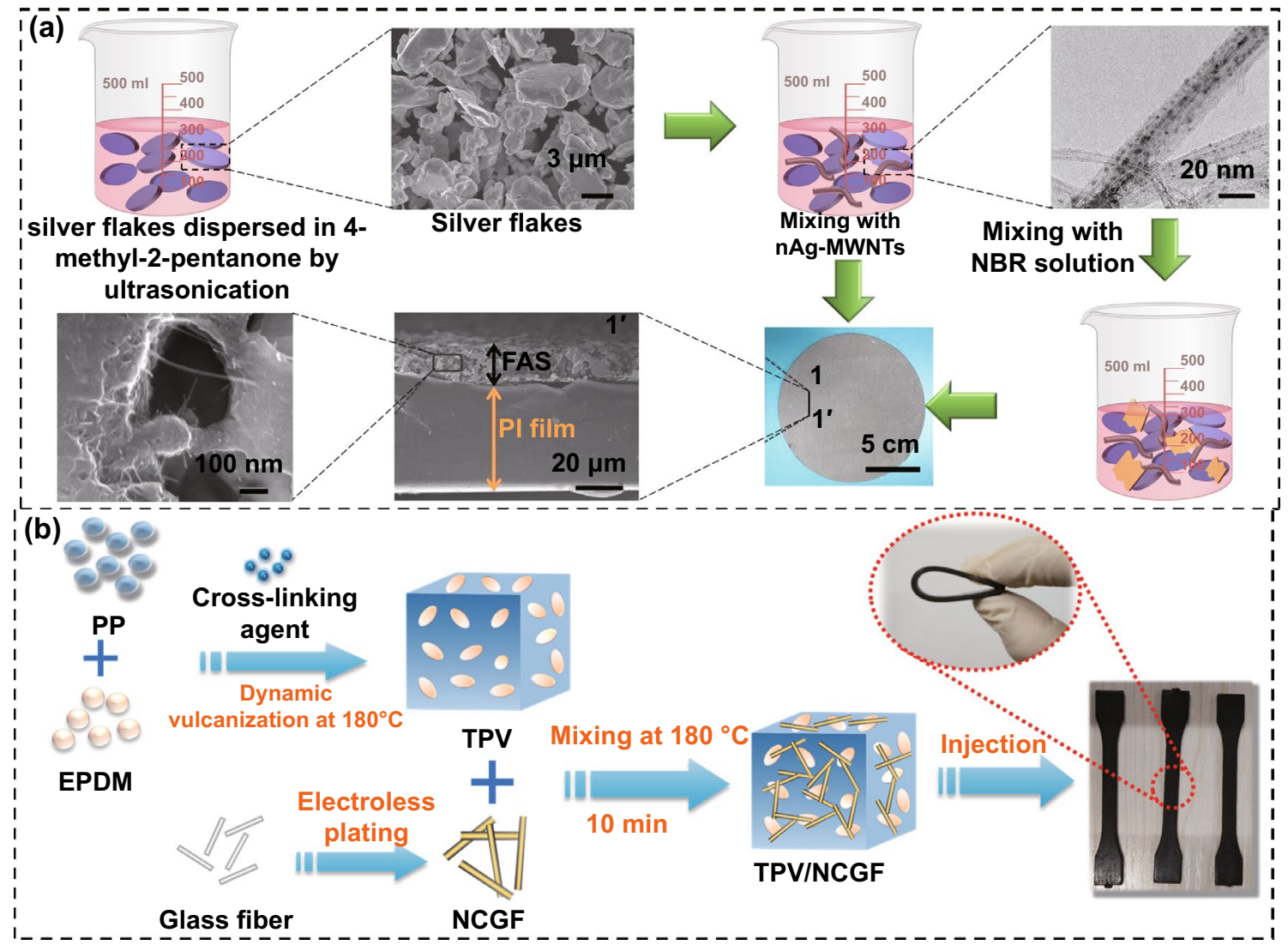

Fig. 5 Schematic illustrating the fabrication of a nAg-MWNTs/NBR and b PP/EPDM/NCGF composites [76, 82]. Copyright @ 2013 Elsevier 
ethylene-propylene-diene monomer (EPDM) as the matrix to prepare the PP/EPDM/NCGF composites via the melt blending and injection molding (Fig. 5b). The EMI SE of the resultant composites reaches $41 \mathrm{~dB}$ when the NCGF content is $15 \mathrm{wt} \%$. The melt blending method has been widely used in actual industrial production due to its good processing performance and low-cost advantage. However, the high shear forces generated by the equipment during the mixing process can damage the structure of the conductive fillers, thereby leading to the decrease of the EMI shielding performances. The polymer matrix composites prepared by the melt blending method require high filler content to achieve the construction of three-dimensional conductive network, so the selection of conductive fillers is limited [83, 84].

\subsubsection{In-situ Polymerization Method}

The in-situ polymerization method refers to uniformly mixing the conductive fillers and the polymer monomers, and the polymerization reaction is initiated by adding an initiator to obtain the polymer matrix EMI shielding composites. This method have no very high shear force, so the surface structure of the fillers is not easy to be destroyed. The insitu polymerization process can promote the uniform and stable dispersion of the conductive fillers, so it has more applications. Wang et al. [85] synthesized the PPy/PDA matrix by an in-situ polymerization and then obtained the PPy/PDA/AgNW composites by mixing with the AgNWs. The results show that when the AgNW content is $50 \mathrm{wt} \%$, the $\sigma$ and EMI SE of PPy/PDA/AgNW composites are 1206 $\mathrm{S} \mathrm{cm}^{-1}$ and $48 \mathrm{~dB}$ respectively, which are 120,000 times and 6.9 times higher than those of pure PPy. Saini et al. [86] fabricated the PANI-MWCNTs composites by an insitu polymerization based on free radical chemical oxidation (Fig. 6a). The results show that when the MWCNT content is $25 \mathrm{wt} \%$, the $\sigma$ and EMI SE of the composites are $19 \mathrm{~S}$ $\mathrm{cm}^{-1}$ and $39 \mathrm{~dB}$, respectively, which are 9.5 times and 1.4 times higher than those of pure PANI. Yun et al. [87] introduced the iron trioxide $\left(\mathrm{Fe}_{2} \mathrm{O}_{3}\right)$ nanoparticles into the PANIMWCNTs composites prepared by in-situ polymerization, and further improved the EMI SE of composites (Fig. 6b). The above researches show that the composites prepared by the in-situ polymerization method exhibit a strong interface interaction between the conductive fillers and polymer matrix, and the conductive fillers have good dispersibility in the polymer matrix. However, the conductive fillers usually require surface modification, which will damage the physical and chemical properties of the fillers [88-90].

\subsection{Segregated Polymer Matrix EMI Shielding Composites}

The segregated polymer matrix EMI shielding composites are prepared by hot pressing of polymer particles coated with conductive fillers on the surface at high temperature. For homogeneous polymer matrix EMI shielding composites, the conductive fillers are randomly dispersed in the polymer matrix. In contrast, the conductive fillers are selectively distributed between the micro-zone interfaces of polymer matrix in the segregated polymer matrix EMI shielding composites. The probability of interlap between the conductive fillers is significantly increased, which facilitates the formation of perfect conductive networks at a low content of conductive fillers. Currently, the conductive fillers used to construct the segregated polymer matrix EMI shielding composites are mainly divided into two categories: micro-scale conductive fillers (graphite and $\mathrm{CB}$ ) and nano-scale conductive fillers (graphene, MWCNTs and MXene) [91-93]. Vovchenko et al. [94] prepared the graphite/PE composites with a segregated structure based on the PE particles coated with graphite by a thermo-compression molding. The results show that the $\sigma$ and EMI SE of graphite/PE composites reach $1.23 \mathrm{~S} \mathrm{~m}^{-1}$ and $26 \mathrm{~dB}$, respectively, when the graphite content is 5.0 vol\%, which are 17.6 times and 2.6 times higher than those with a homogeneous structure, respectively. Cui et al. [95] prepared the $\mathrm{CB} /$ ultra-high molecular weight polyethylene (UHMWPE) composites via the hot pressing of UHMWPE particles coated with CB obtained by a highspeed ball milling. The results show that the $\mathrm{CB}$ is selectively distributed in the interfacial region of the UHMWPE matrix, forming a typical segregated structure (Fig. 7c). The $\sigma$ and EMI SE of the CB/UHMWPE composites are $14.1 \mathrm{~S}$ $\mathrm{m}^{-1}$ and $33 \mathrm{~dB}$, respectively, with the CB content of $15 \mathrm{wt} \%$. Yan et al. [96] coated the rGO on the surface of polystyrene (PS) particles by the in-situ reduction, and then compressed the obtained composite particles into the segregated $\mathrm{rGO} /$ PS composites by a high-pressure solid-phase compression molding (Fig. 7a). The rGO is selectively distributed in the interface between PS particles, instead of uniformly distributed in the PS matrix. The rGO/PS composites with a 

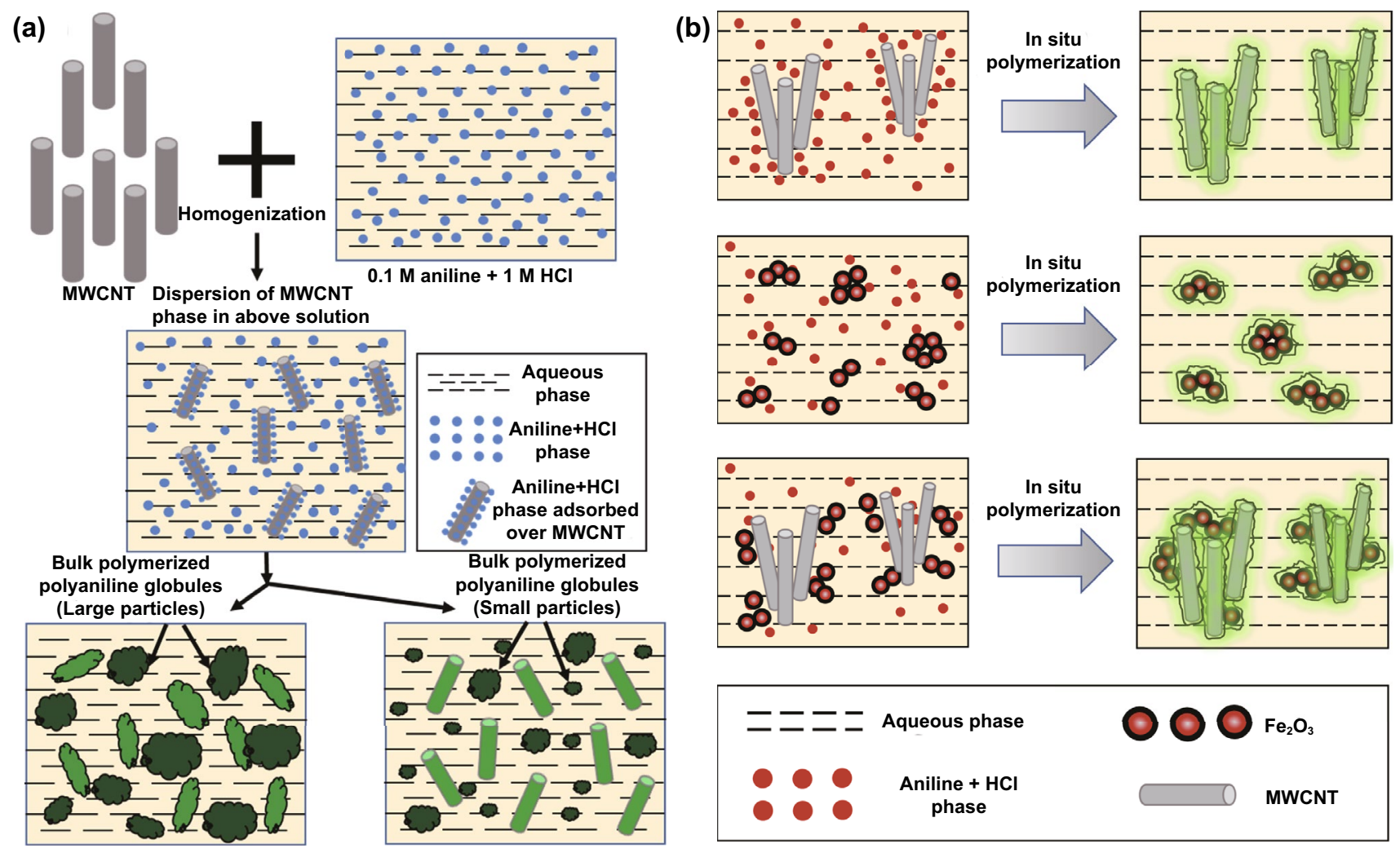

Fig. 6 Schematic illustrating the fabrication of a PANI-MWCNTs and b PANI-MWCNTs/ $/ \mathrm{Fe}_{2} \mathrm{O}_{3}$ composites [86, 87]. Copyright @ 2008 Elsevier

segregated structure can effectively reduce the percolation threshold and significantly improve the electrical conductivity. The EMI SE of the segregated rGO/PS composites reaches $45 \mathrm{~dB}$ when the rGO content is $3.47 \mathrm{wt} \%$. Sun et al. [97] loaded the negatively charged MXene onto the surface of positively charged PS microspheres by an electrostatic self-assembly, and then prepared the highly conductive segregated MXene@PS nanocomposites by pressing (Fig. 7b). The MXene forms the effective three-dimensional conductive networks in the PS matrix. The resultant MXene@PS nanocomposites not only exhibit a low percolation threshold of $0.26 \mathrm{vol} \%$, but also have an excellent $\sigma$ of $1081 \mathrm{~S} / \mathrm{m}$ and an high EMI SE of $62 \mathrm{~dB}$.

The above studies show that although the micro-scale conductive fillers such as graphite and CB are low-cost and not easily agglomerated in the polymer matrix, the $\sigma$ and EMI SE of the prepared polymer matrix composites are still not satisfied even at a high content of conductive fillers. The nano-scale conductive fillers such as rGO and MXene can easily form the conductive pathways within the polymer matrix due to their large specific surface area and excellent conductive property, thereby improving the $\sigma$ and EMI SE of the polymer matrix composites. However, the nano-scale conductive fillers are costly and highly prone to agglomeration in the polymer matrix. In addition, the conductive fillers form a single continuous network structure and the polymer particles tend to exist in isolation after the polymer particles covered with conductive fillers are hot pressed, resulting in poor mechanical properties of polymer matrix EMI shielding composites. Therefore, while maintaining the excellent EMI shielding performance of segregated polymer matrix EMI shielding composites, further optimization of mechanical properties and manufacturing costs is the key to achieving large-scale applications [98-100].

\subsection{Porous Polymer Matrix EMI Shielding Composites}

The porous polymer matrix EMI shielding composites use polymer matrix as the support skeleton, which is then modified or loaded with conductive fillers. Compared with homogeneous and segregated polymer matrix EMI shielding 


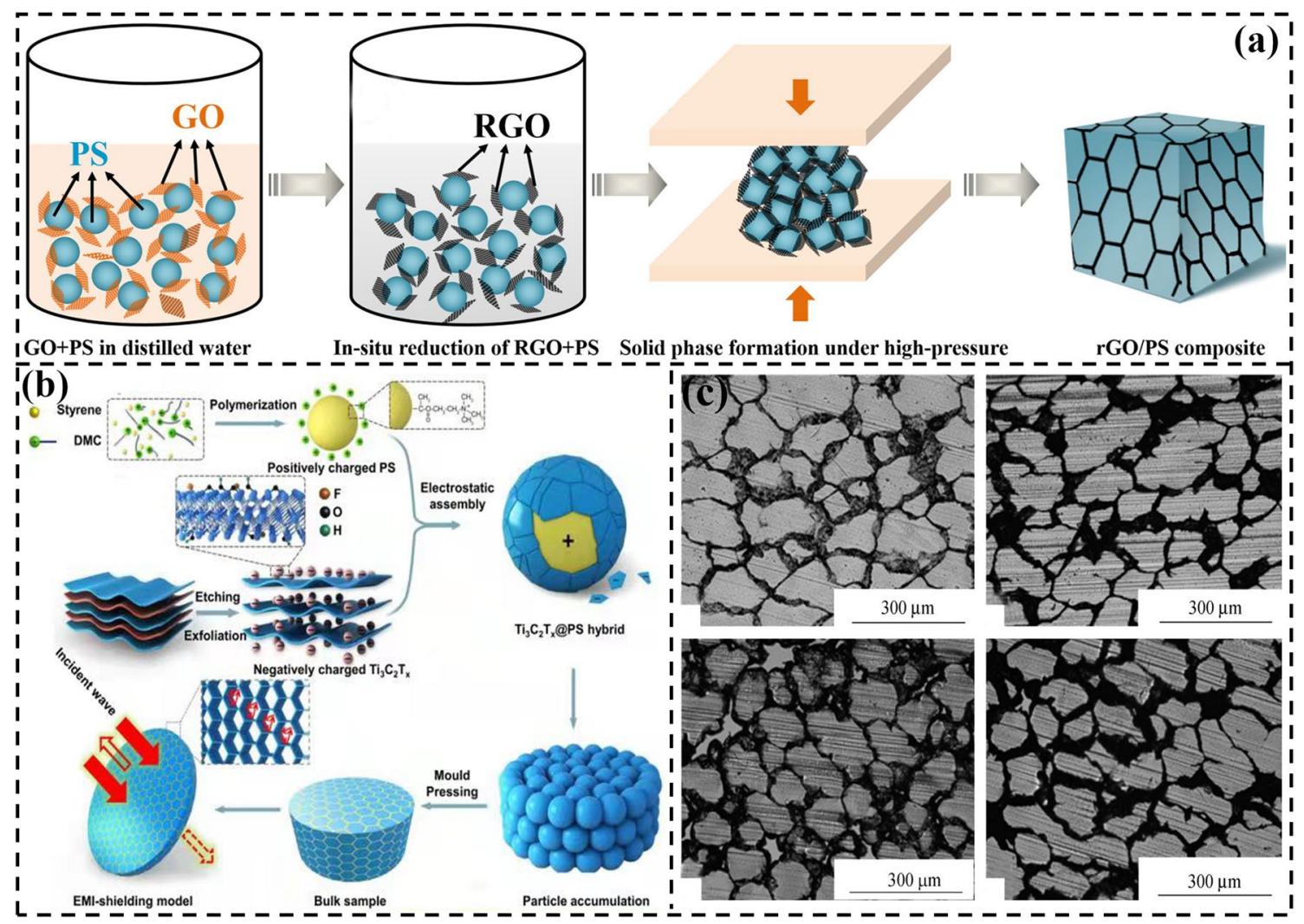

Fig. 7 Schematic illustrating the fabrication of a rGO/PS and b MXene@PS composites [96, 97]. $\mathbf{c}$ SEM images of CB/UHMWPE composites [95]. Copyright @ 2014 Wiley-VCH. Copyright @ 2017 Wiley-VCH

composites, the porous polymer matrix EMI shielding composites have the advantages of low cost, good toughness, and low density. At the same time, the porous structure can contribute to the multiple reflection and absorption of electromagnetic waves, which will further improve the EMI shielding performance of the composites. Currently, the foaming method, sol-gel method and template method are widely used to prepare the porous polymer matrix EMI shielding composites [101-103].

\subsubsection{Foaming Method}

The foaming process includes the chemical foaming method and physical foaming method. The chemical foaming method refers to mixing a foaming agent (azo compounds, sulfonyl hydrazide compounds and nitroso compounds, etc.) into the polymer matrix composites, and the foaming agent can decompose gas during the heating process to foam the composites. The physical foaming method means that the gas produced by the supercritical fluids $\left(\mathrm{CO}_{2}, \mathrm{~N}_{2}\right.$, butane, pentane, etc.) in a thermodynamically unstable state is nucleated, grown, and stabilized to achieve the foaming of polymer matrix EMI shielding composites [104]. Eswaraiah et al. [105] prepared the functionalized graphene (f-G)/ PVDF composites with a porous structure by chemical foaming using functionalized graphene ( $\mathrm{f}-\mathrm{G}$ ) as the conductive filler, PVDF as the polymer matrix, and azobisisobutyronitrile (AIBN) as the foaming agent. The results show that when the $\mathrm{f}-\mathrm{G}$ content is $0.5 \mathrm{wt} \%$, the EMI SE of the $\mathrm{f}-\mathrm{G} /$ PVDF composites are 18 and $20 \mathrm{~dB}$ at the frequencies of 1-8 and 8-12 GHz, respectively. Zhang et al. [106] prepared the PMMA/GNPs-MWCNTs composites with porous structures by the direct blending and supercritical $\mathrm{CO}_{2}$ foaming techniques, using MWCNTs and graphene nanoplates (GNPs) as the conductive fillers and polymethyl methacrylate (PMMA) as the matrix. (Fig. 8a). The results show that when the contents of MWCNTs and GNPs are $4 \mathrm{wt} \%$ and $1.5 \mathrm{wt} \%$, respectively, the EMI SE of the porous PMMA/GNPs-MWCNTs 
composites reaches $36 \mathrm{~dB}$, which is much higher than that of the homogeneous composites prepared by the direct blending. Fan et al. [107] prepared the silver nanosheets (AgNS)/ epoxy composites with porous structures by the direct blending and supercritical $\mathrm{CO}_{2}$ foaming technique, using AgNS as the conductive filler and epoxy resin as the matrix (Fig. 8b). When the AgNS content is $20 \mathrm{wt} \%$, the EMI SE of the porous AgNS/epoxy composites reaches $42 \mathrm{~dB}$, which is much higher than that of the composites with the homogeneous structure prepared by direct blending. The above researches show that the foaming method for preparing the EMI shielding composites are suitable for a variety of polymer matrices, and the conductive fillers can be dispersed again during the foaming process. However, the improvement of EMI SE for polymer matrix composites by a single foaming technique is limited, which is far from that of metal materials. In practical applications, it is also necessary to combine other methods to further improve the EMI shielding performance of the composites.

\subsubsection{Sol-gel Method}

The sol-gel method used to prepare porous polymer matrix EMI shielding composites is very common in laboratory research. Usually, the highly active conductive fillers and polymer monomers are uniformly mixed in the liquid phase to form a stable sol system. The sol forms a gel with threedimensional network structure in solution by hydrolysis reaction, condensation reaction and hydrogen bonding. The gel is freeze-dried to obtain porous polymer matrix EMI shielding composites [108]. Zeng et al. [109] uniformly mixed the MWCNTs and waterborne polyurethane (WPU) in an aqueous solution to form a stable sol system, which was directly freeze-dried to obtain the MWCNTs/WPU aerogels with an anisotropic porous structure. The results show that the EMI SE of the MWCNTs/WPU aerogels reaches $50 \mathrm{~dB}$ at a density of $126 \mathrm{mg} / \mathrm{cm}^{3}$. The excellent EMI shielding performance is attributed to the highly conductive network of MWCNTs, the anisotropic porous structure and the

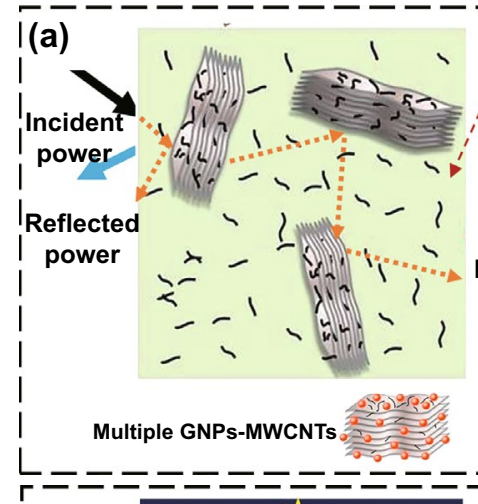

I(b)

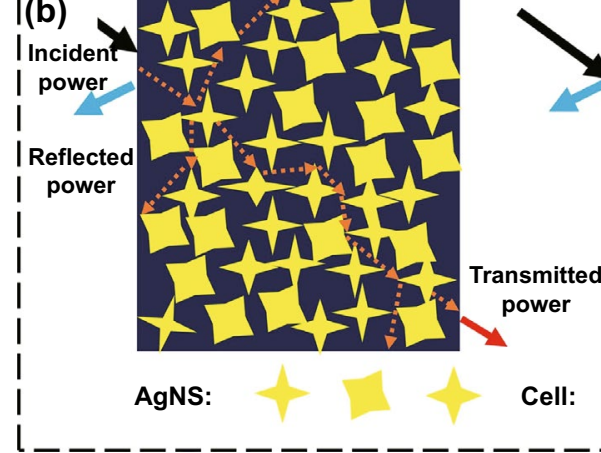

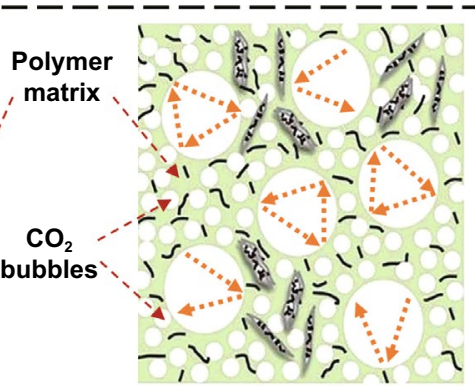

Expansion graphene-MWCNTs 2
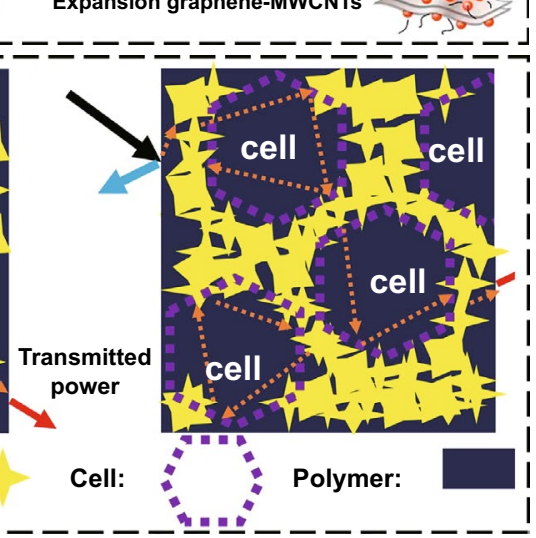
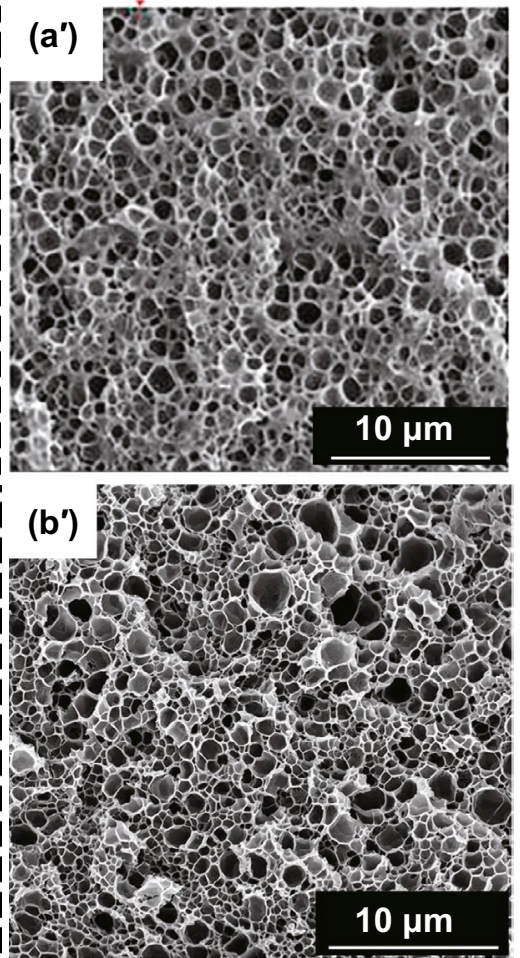

Fig. 8 Schematic diagram and SEM images of a PMMA/GNPs-MWCNTs and b AgNS/epoxy composites with homogeneous and porous structures [106, 107]. Copyright $@ 2018$ Elsevier. Copyright $@ 2019$ Elsevier 
polarization effect between MWCNTs and WPU matrix. Lu et al. [110] first mixed the GO and lignin homogeneously in an aqueous solution to form a stable sol-gel system. Then the system was unidirectionally freeze-dried to prepare the ultralight GO/lignin aerogels with micro-channel. Finally, the aerogels were thermally reduced to obtain the reduced GO/lignin-derived carbon (RGO/LDC) composites (Fig. 9a). The introduction of lignin enhances the interfacial polarization effect and the absorption of electromagnetic waves in the RGO/LDC composites. The obtained composites achieve an EMI SE of $49 \mathrm{~dB}$ at an ultra-low density of $8.0 \mathrm{mg} \mathrm{cm}^{-3}$, which is higher than that of a single-phase RGO foam. Nyström et al. [111, 112] dispersed the AgNW and MXene in the CNF sol system, and then directly freezedried to prepare the AgNW/CNF and MXene/CNF aerogels, respectively (Fig. 9b, c). The EMI SE of the AgNW/CNF aerogel reaches $40 \mathrm{~dB}$ at a density of $1.7 \mathrm{mg} \mathrm{cm}^{-3}$, while that of the MXene/CNF aerogel reaches $35 \mathrm{~dB}$ at a density of $1.5 \mathrm{mg} \mathrm{cm}^{-3}$. The above researches show that the polymer matrix composites prepared by the sol-gel method achieve a rapid increase in EMI SE per unit density due to their internal porous structure. However, the polymer matrix networks prepared by this method have weak connection strength, resulting in poor mechanical properties of the composites [113, 114].

\subsubsection{Template Method}

The template method refers to the preparation of porous polymer matrix EMI shielding composites by uniformly attaching conductive fillers to the surface of porous polymer matrix skeletons through chemical plating, chemical vapor deposition (CVD), electrostatic adsorption, etc. The conductive fillers are oriented and continuously distributed along the polymer matrix porous framework, which helps to form a conductive network efficiently, thereby improving the EMI shielding performance of the composites [115]. Lin et al. [116] immersed the melamine sponge (MS) in the AgNW/ polyvinyl butyral (PVB) solution so that the AgNW/PVB was evenly coated on the surface of the MS framework, which was dried to obtain the AgNW/PVB/MS sponge (Fig. 10a). The EMI SE of the AgNW/PVB/MS sponge with a thickness of $5 \mathrm{~mm}$ reaches $60 \mathrm{~dB}$, which is higher than that of a commercial EMI shielding sponge with the same thickness. Nguyen et al. [117] successively deposited the graphene (GF), $\mathrm{Fe}_{3} \mathrm{O}_{4} @ \mathrm{MXene}$ and PDMS on the surface of the nickel foam
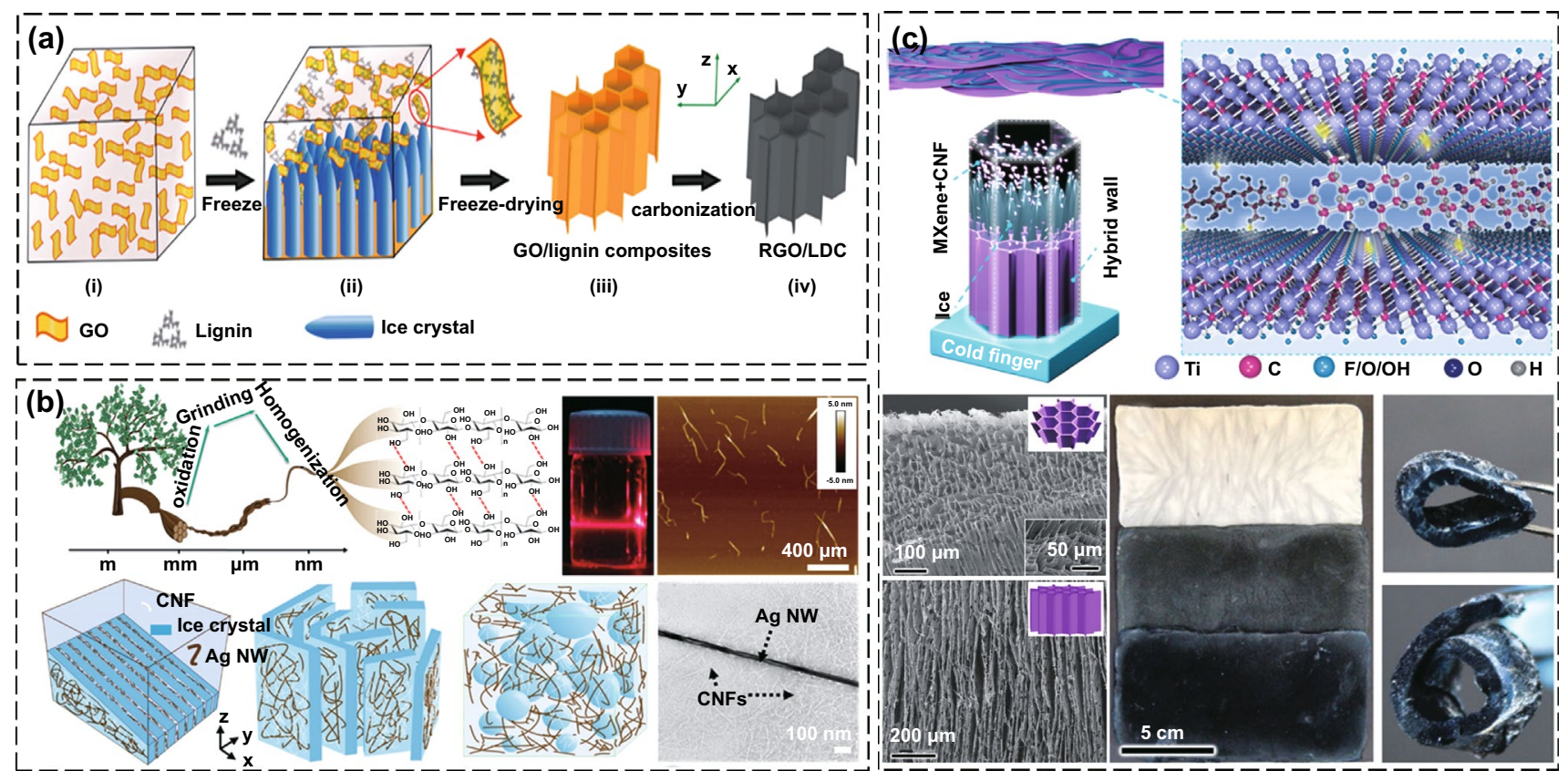

Fig. 9 Schematic illustrating the fabrication, SEM images and digital photos of a RGO/LDC composites, b AgNW/CNF aerogels, and c MXene/CNF aerogels [110-112]. Copyright (C) 2018 American Chemical Society. Copyright @ 2020 Wiley-VCH. Copyright @ 2020 American Chemical Society 
template through a CVD process. The $\mathrm{Fe}_{3} \mathrm{O}_{4} @ \mathrm{MXene} / \mathrm{GF} /$ PDMS foam was obtained after the nickel foam template was etched by a ferric chloride solution (Fig. 10b). The EMI SE of $\mathrm{Fe}_{3} \mathrm{O}_{4} @$ MXene/GF/PDMS foam is 80 and $77 \mathrm{~dB}$ in X-band and Ku-band, respectively. Gu et al. [118] reported the PU@ PDA@Ag sponge by a bio-response template method, which could be obtained by two steps: (i) PDA was decorated on the surface of PU sponge by dopamine self-polymerization. (ii) Ag nanoparticles were in-situ grown on the surface of PU sponge by electroless plating. The EMI SE of the obtained PU@PDA@Ag sponge is as high as $84 \mathrm{~dB}$ at a thickness of $5 \mathrm{~mm}$ (Fig. 10c). The above researches show that the advantages of template method include the low density, the simplicity of preparation process, and the possibility of large-scale preparation. However, if the porous composites prepared by template method are deformed during applications, the conductive fillers are easily detached from the polymer matrix skeleton, which will affect the EMI shielding lifetime of the composites [119, 120].

\subsection{Layered Polymer Matrix EMI Shielding Composites}

The layered polymer matrix EMI shielding composites are a class of materials with a layered structure. The electromagnetic waves can be reflected for multiple times inside the composites due to the layered structure, thereby improving their EMI shielding performance greatly. The lightweight and flexible polymer matrix EMI shielding films are the most representative type of material with a layered structure, and has attracted wide attention from researchers. At present, the preparation of polymer matrix EMI shielding films is mainly through vacuum filtration method, coating method and polymer-assisted method [121-123].

\subsubsection{Vacuum Filtration Method}

The vacuum filtration method refers to prepare the polymer matrix EMI shielding films by removing the solvent in the mixed solution of conductive fillers and polymer matrix under pressure difference. The films prepared by the vacuum filtration method have an obvious layered structure and can efficiently reflect the electromagnetic waves for multiple times. Ma et al. [124] used the two-dimensional MXene and one-dimensional AgNWs as the conductive functional layer and aramid nanofibers (ANFs) as the high-performance enhancement layer to fabricate the flexible and high-strength ANF-MXene/AgNW composite films with a bilayer structure by the vacuum-assisted filtration and hot-press molding techniques (Fig. 11a). This work provides theoretical and
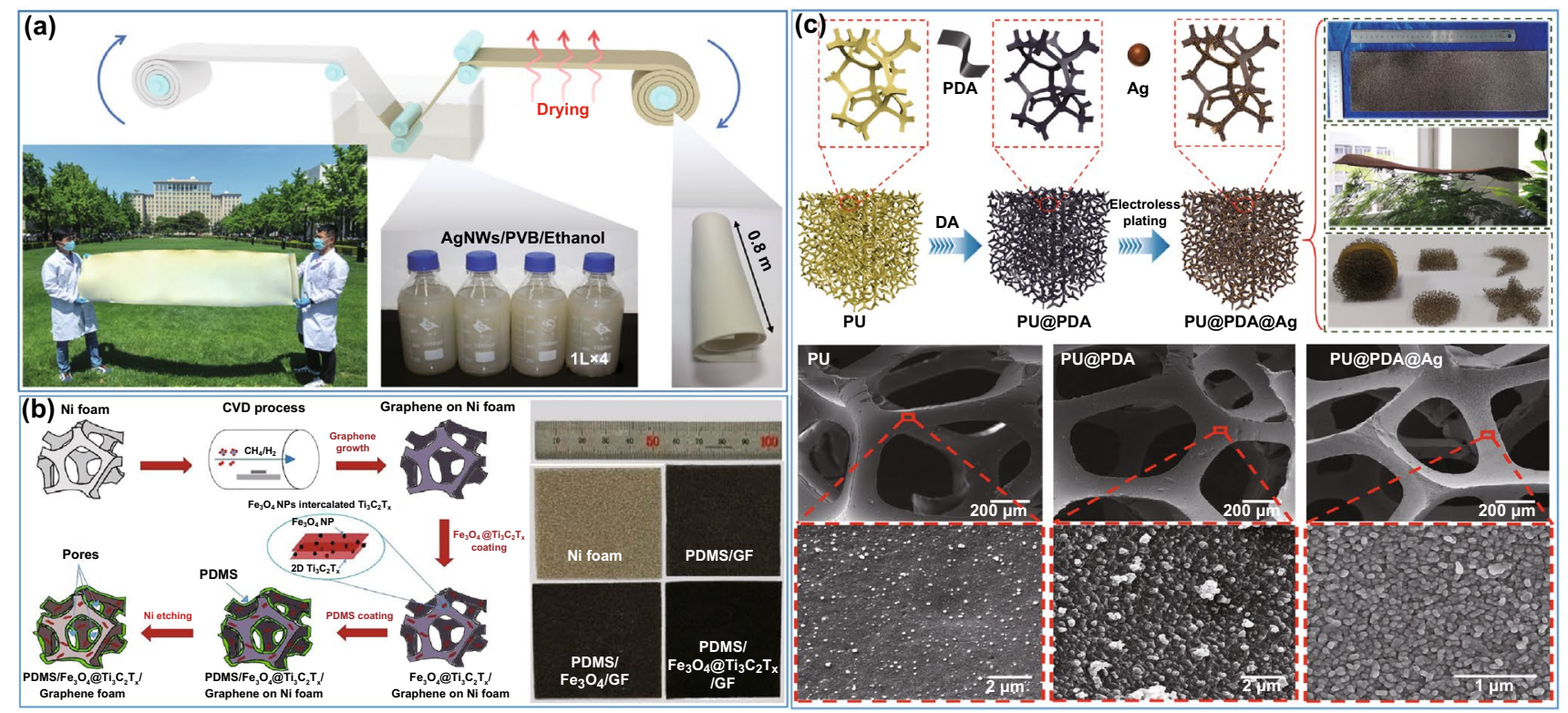

Fig. 10 Schematic illustrating the fabrication and SEM images of a AgNW/PVB/MS sponges, $\mathbf{b} \mathrm{Fe}_{3} \mathrm{O}_{4} @ \mathrm{MXene} / \mathrm{GF} / \mathrm{PDMS}$ foams, and $\mathbf{c}$ PU@ PDA@Ag sponges [116-118]. Copyright @ 2019 Wiley-VCH. Copyright @ 2020 Elsevier 
technical guidance for the design and fabrication of flexible and high-strength layered polymer EMI shielding composites. The EMI SE of the ANF-MXene/AgNW films with a thickness of $0.091 \mathrm{~mm}$ is about $80 \mathrm{~dB}$ in the $\mathrm{X}$-band, which is higher than that of the films with a homogeneous structure with the same MXene/AgNW content. Zhou et al. [125] prepared the CNF@MXene multilayer films with an alternating structure by an alternating vacuum filtration method using CNF and MXene as raw materials (Fig. 11b). The EMI SE of the CNF@MXene multilayer films with a thickness of $0.035 \mathrm{~mm}$ in the X-band is about $40 \mathrm{~dB}$, which is higher than that of the films with a homogeneous structure. The main reason is that the alternating multilayer structure of CNF@ MXene films increases the "zigzag" reflection mechanism of electromagnetic waves. Gu et al. [126] first co-doped the modified polyaniline (c-PANI) with dodecyl benzene sulfonic acid and hydrochloric acid, then prepared less layers of MXene using the ionic intercalation and ultrasound-assisted techniques, and finally prepared the MXene/c-PANI EMI shielding films by a vacuum filtration method (Fig. 11c). The $\sigma$ and EMI SE of the MXene/c-PANI EMI shielding films with a thickness of $0.040 \mathrm{~mm}$ are $24.4 \mathrm{~S} \mathrm{~cm}^{-1}$ and $36 \mathrm{~dB}$, respectively, which are 81 times and 2.3 times higher than those of the pure c-PANI films. It can be seen that the thickness of the EMI shielding films prepared by vacuum filtration method is easy to control and the utilization rate of raw materials is relatively high. However, the area of the EMI shielding films is restricted by the size of the equipment, and the system containing two-dimensional sheet materials takes a long time to form films by vacuum filtration $[127,128]$.

\subsubsection{Coating Method}

The coating method refers to the preparation of polymer matrix EMI shielding films by curing a mixed system containing conductive fillers and resin matrix in an appropriate mold. Obviously, the coating method is relatively simple and widely used in actual production. In order to build a more complete conductive network inside the EMI shielding films, the viscosity and curing time of the resin matrix are the keys to the process. Sheng et al. [40] constructed
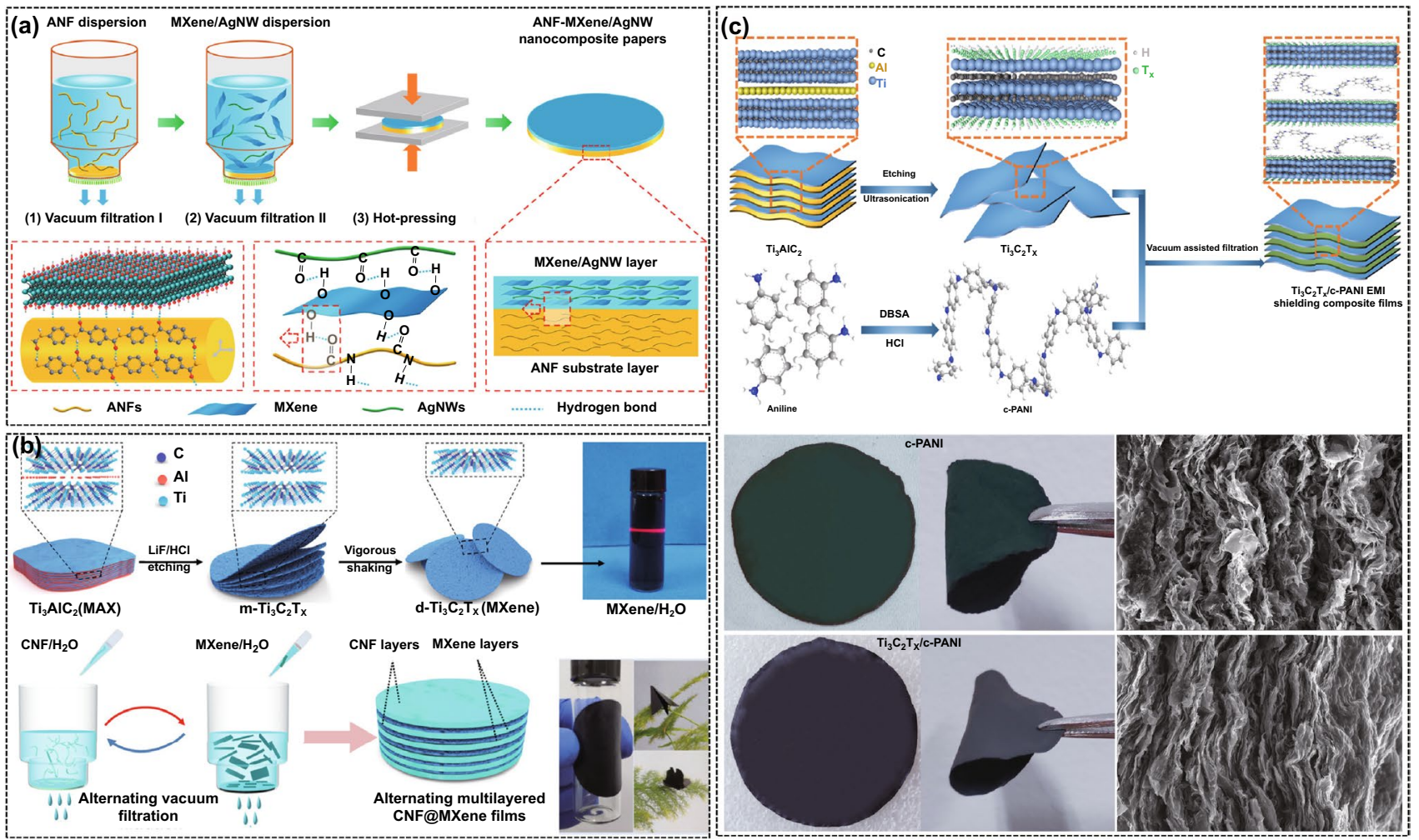

Fig. 11 Schematic illustrating the fabrication and SEM images of a ANF-MXene/AgNW, b CNF@MXene, and c MXene/c-PANI composite films [124-126]. Copyright (C) 2020 American Chemical Society. Copyright () 2019 Elsevier 
the ordered multilayer $\mathrm{Fe}_{3} \mathrm{O}_{4} @ \mathrm{rGO} / \mathrm{MWCNTs} / W P U$ films by the layer-by-layer coating method. The $\mathrm{Fe}_{3} \mathrm{O}_{4} @ \mathrm{rGO}$ and MWCNTs provide negative magnetic gradient and positive electrical conductivity gradient, respectively (Fig. 12a). The EMI SE of $\mathrm{Fe}_{3} \mathrm{O}_{4} @ \mathrm{rGO} /$ MWCNTs/WPU films reaches $35.9 \mathrm{~dB}$ when the MWCNT content is $60 \%$. Jin et al. [129] prepared the multilayer PVA/MXene films by alternate coating using PVA and MXene as raw materials. The continuous MXene layers provide the compact networks for conducting electrons, allowing the multilayer PVA/MXene films to exhibit excellent EMI shielding performance. The PVA/Mxene films with $27 \mu \mathrm{m}$ thickness exhibits the $\sigma$ of $716 \mathrm{~S} \mathrm{~m}^{-1}$ and the maximum EMI SE of $44.4 \mathrm{~dB}$ when the MXene content is $19.5 \mathrm{wt} \%$. Ren et al. [130] first prepared the FeCo@rGO/WPU hybrid system using the reduced graphene oxide grafted with FeCo alloy (FeCo@ rGO) as filler and WPU as matrix, and then applied the hybrid system to the encapsulation of silver-plated nonwoven fabric (Ag/ NWF) by coating method to obtain the Ag/NWF/FeCo@ rGO/WPU films (Fig. 12b). The EMI SE of the Ag/NWF/ FeCo@rGO/WPU films reaches $77 \mathrm{~dB}$ when the Ag and FeCo@rGO contents are $10.5 \mathrm{wt} \%$ and $10 \mathrm{wt} \%$, respectively. $\mathrm{Xu}$ et al. [131] prepared the $\mathrm{Fe}_{3} \mathrm{O}_{4} @ \mathrm{rGO} / \mathrm{T}-\mathrm{ZnO} / \mathrm{Ag} / \mathrm{WPU}$ films by the coating method using $\mathrm{Fe}_{3} \mathrm{O}_{4} @ \mathrm{rGO}$ and silverplated tetra-needle $\mathrm{ZnO}$ whiskers ( $\mathrm{T}-\mathrm{ZnO} / \mathrm{Ag}$ ) as fillers and WPU as matrix (Fig. 12c). Because of the differences of $\mathrm{Fe}_{3} \mathrm{O}_{4} @ \mathrm{rGO}$ and $\mathrm{T}-\mathrm{ZnO} / \mathrm{Ag}$ in density, a gradient structure is automatically formed during the film formation process. The $\mathrm{Fe}_{3} \mathrm{O}_{4} @ \mathrm{rGO}$ is uniformly distributed throughout the thickness range of the film, forming the effective threedimensional electromagnetic wave absorption network. The $\mathrm{T}-\mathrm{ZnO} / \mathrm{Ag}$ is uniformly deposited at the bottom of the film, forming the effective two-dimensional electromagnetic wave reflection network. When electromagnetic waves penetrate the $\mathrm{Fe}_{3} \mathrm{O}_{4} @ \mathrm{rGO} / \mathrm{T}-\mathrm{ZnO} / \mathrm{Ag} / \mathrm{WPU}$ films, its specific structure can trigger the "absorption-reflection-reabsorption" mechanism. The EMI SE of the $\mathrm{Fe}_{3} \mathrm{O}_{4} @ \mathrm{rGO} / \mathrm{T}-\mathrm{ZnO} / \mathrm{Ag} /$ WPU films with a thickness of $0.5 \mathrm{~mm}$ reaches $87 \mathrm{~dB}$ under the contents of 0.8 vol\% $\mathrm{Fe}_{3} \mathrm{O}_{4} @ \mathrm{rGO}$ and $5.7 \mathrm{vol} \% \mathrm{~T}-\mathrm{ZnO} /$ $\mathrm{Ag}$. The above researches show that the EMI shielding films prepared by the coating method are not restricted by the equipment and can be produced on a large scale. The EMI shielding films with a gradient structure can be prepared by using the density difference of the conductive fillers, thereby making the films have excellent electromagnetic wave absorption performance. However, the coating method (a)
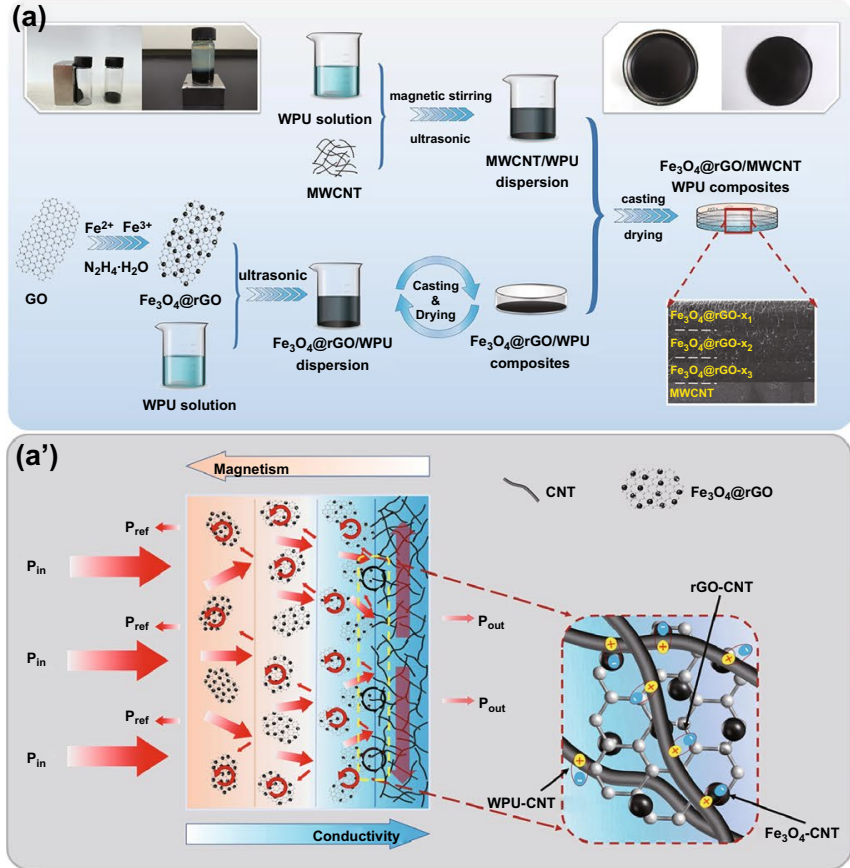
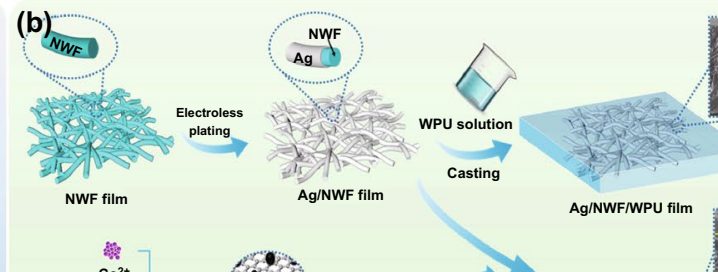

Ag/NWF/WPU film
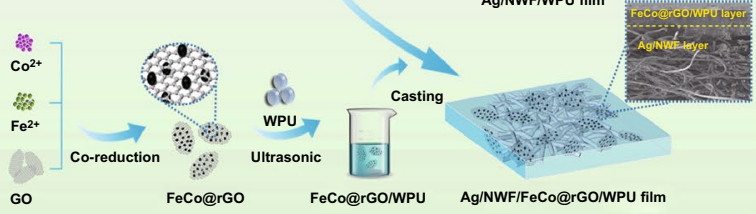

(c)
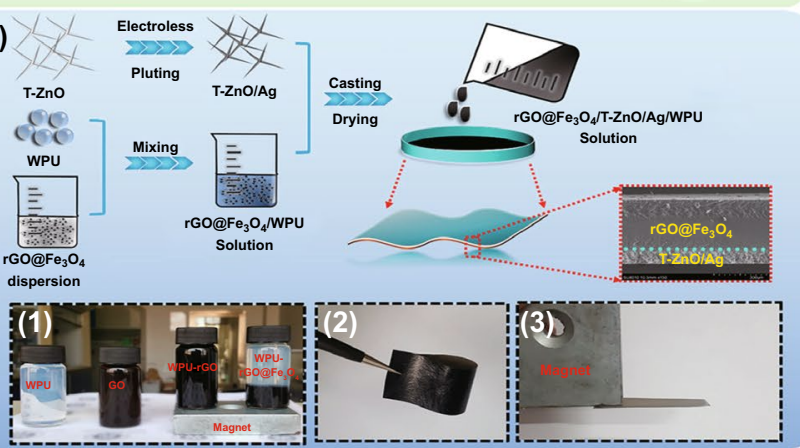

Fig. 12 Schematic illustrating the fabrication of $\mathbf{a} \mathrm{Fe}_{3} \mathrm{O}_{4} @ \mathrm{rGO} / \mathrm{MWCNTs} / \mathrm{WPU}, \mathbf{b} \mathrm{CNF} @ \mathrm{MXene}$, and $\mathbf{c} \mathrm{Ti}_{3} \mathrm{C}_{2} \mathrm{~T}_{\mathrm{x}} / \mathrm{c}-\mathrm{PANI}$ composite films $[40$, 130, 131]. Copyright @ 2019 Elsevier. Copyright @ 2020 Elsevier. Copyright @ 2018 American Chemical Society 
also faces some problems, such as the time-consuming curing process of the resin matrix, and the interlayer of the films are not dense [132-134].

\subsubsection{Polymer-assisted Method}

The polymer-assisted method refers to the direct deposition of conductive fillers on the surface of the polymer matrix films through laser printing, high-pressure spraying, sputtering deposition, etc., to prepare the polymer matrix EMI shielding films. The method is the main technical tool for the preparation of transparent EMI shielding films [30, 135, 136]. Wang et al. [137] used the sputtering deposition technique to deposit copper-doped silver and indium tin oxide (ITO) films sequentially on a polyethylene terephthalate (PET) film substrate. The obtained $\mathrm{Cu}-\mathrm{Ag} / \mathrm{ITO} / \mathrm{PET}$ films transmit $96.5 \%$ of visible light and show an EMI SE of $26 \mathrm{~dB}$ over the wide frequency range of $32 \mathrm{GHz}$. Gu et al. [138] first constructed a regular AgNW grid on the glass surface by a laser printing technique, and then transferred the AgNW grid to the PVA/PET substrate by a printing technique, and finally prepared the AgNW/PVA/PET films by a hot pressing. The resultant films obtain an EMI SE of $44 \mathrm{~dB}$ and a visible light transmittance of $67.8 \%$. Zhu et al. [139] first coated the AgNW network on the glass substrate by the Meyer rod coating method, and then encapsulated the AgNW network through poly dimethyl diallyl ammonium chloride (PDDA) to obtain the AgNW/PDDA films. The EMI SE and visible light transmittance of the resultant films are $31 \mathrm{~dB}$ and $91.3 \%$, respectively. Chen et al. [140] successively constructed the dense AgNW and MXene conductive grids on PET substrates using the high-pressure air-assisted spraying technology (Fig. 13). The EMI SE and visible light transmittance of the obtained films can reach $49 \mathrm{~dB}$ and $83 \%$, respectively. Although the polymer-assisted method can quickly and continuously prepare composite films, the connection strength between the conductive filler network and the polymer matrix is not high, which easily leads to interface separation [141].

\subsection{Preformed Polymer Matrix EMI Shielding Composites}

The preformed polymer matrix EMI shielding composites are a class of materials in which the conductive fillers are pre-constructed in the resin matrix with a specific threedimensional structure by freeze-drying, hydrothermal, or CVD methods [142, 143]. The conductive fillers in the preformed composites have formed a stable three-dimensional conductive framework, and the polymer matrix with very low viscosity does not destroy the original conductive network during the backfilling process. Therefore, the composites can achieve rapid improvement of EMI SE with low contents of conductive fillers [144, 145]. Gao et al. [146] prepared a biaxially arranged graphene network with a laminar structure by bi-directional freezing technique, which was thermally reduced at $2500{ }^{\circ} \mathrm{C}$ and impregnated with PDMS to obtain the graphene/PDMS composites with a mother-of-pearl-like structure (Fig. 14a). When the graphene content is $0.42 \mathrm{wt} \%$, the EMI SE values of the graphene/ PDMS composites in the parallel and perpendicular directions to the graphene plane reach 16 and $42 \mathrm{~dB}$, respectively. Fang et al. [147] first prepared the graphene foam (GF) by a CVD method using nickel foam as a template, then grew $\mathrm{Fe}_{3} \mathrm{O}_{4}$ in situ on the surface of GF to obtain $\mathrm{GF} / \mathrm{h}-\mathrm{Fe}_{3} \mathrm{O}_{4}$, and finally obtained the $\mathrm{GF} / \mathrm{h}-\mathrm{Fe}_{3} \mathrm{O}_{4} / \mathrm{PDMS}$ composites by impregnating the $\mathrm{GF} / \mathrm{h}-\mathrm{Fe}_{3} \mathrm{O}_{4}$ with PDMS. The composites exhibit an EMI SE of $70 \mathrm{~dB}$ when the GF/h-Fe ${ }_{3} \mathrm{O}_{4}$ content is $12 \mathrm{wt} \%$. Shen et al. [148] prepared the carbon skeleton with a continuous structure by carbonizing the natural wood, which was backfilled with epoxy resin to prepare the epoxy/ wood-derived carbon composites. The $\sigma$ and EMI SE of the obtained composites are $12.5 \mathrm{~S} \mathrm{~m}^{-1}$ and $27.8 \mathrm{~dB}$, respectively, when the carbon content is $7.0 \mathrm{vol} \%$. In our previous works, a series of preformed polymer matrix EMI shielding composites with the controllable structure were prepared. $\mathrm{Gu}$ et al. [149] first prepared the homogeneous hybrid system of amino-functionalized $\mathrm{Fe}_{3} \mathrm{O}_{4}\left(\mathrm{NH}_{2}-\mathrm{Fe}_{3} \mathrm{O}_{4}\right)$ nanoparticles, GO and L-ascorbic acid, then the hybrid system was hydrothermally reacted to obtain the $\mathrm{Fe}_{3} \mathrm{O}_{4}$ /graphene aerogel $\left(\mathrm{Fe}_{3} \mathrm{O}_{4} / \mathrm{GA}\right)$, which was thermally annealed and backfilled with epoxy resin to obtain the $\mathrm{Fe}_{3} \mathrm{O}_{4}$ /thermally annealed GA ( $\mathrm{Fe}_{3} \mathrm{O}_{4} /$ TAGA)/epoxy composites (Fig. 14b). When the mass ratio of $\mathrm{GO}$ to $\mathrm{NH}_{2}-\mathrm{Fe}_{3} \mathrm{O}_{4}$ is $2: 1$ and the total $\mathrm{Fe}_{3} \mathrm{O}_{4} /$ TAGA content is $2.7 \mathrm{wt} \%$, the EMI SE of the resultant composites reaches $35 \mathrm{~dB}$, which is much higher than that of the epoxy composites prepared by the direct blending method with the same fillers content. Furthermore, Gu et al. [150] prepared the anisotropic and highly conductive $\mathrm{CNF} / \mathrm{MXene}$ aerogel (CTA) based on the unidirectional 


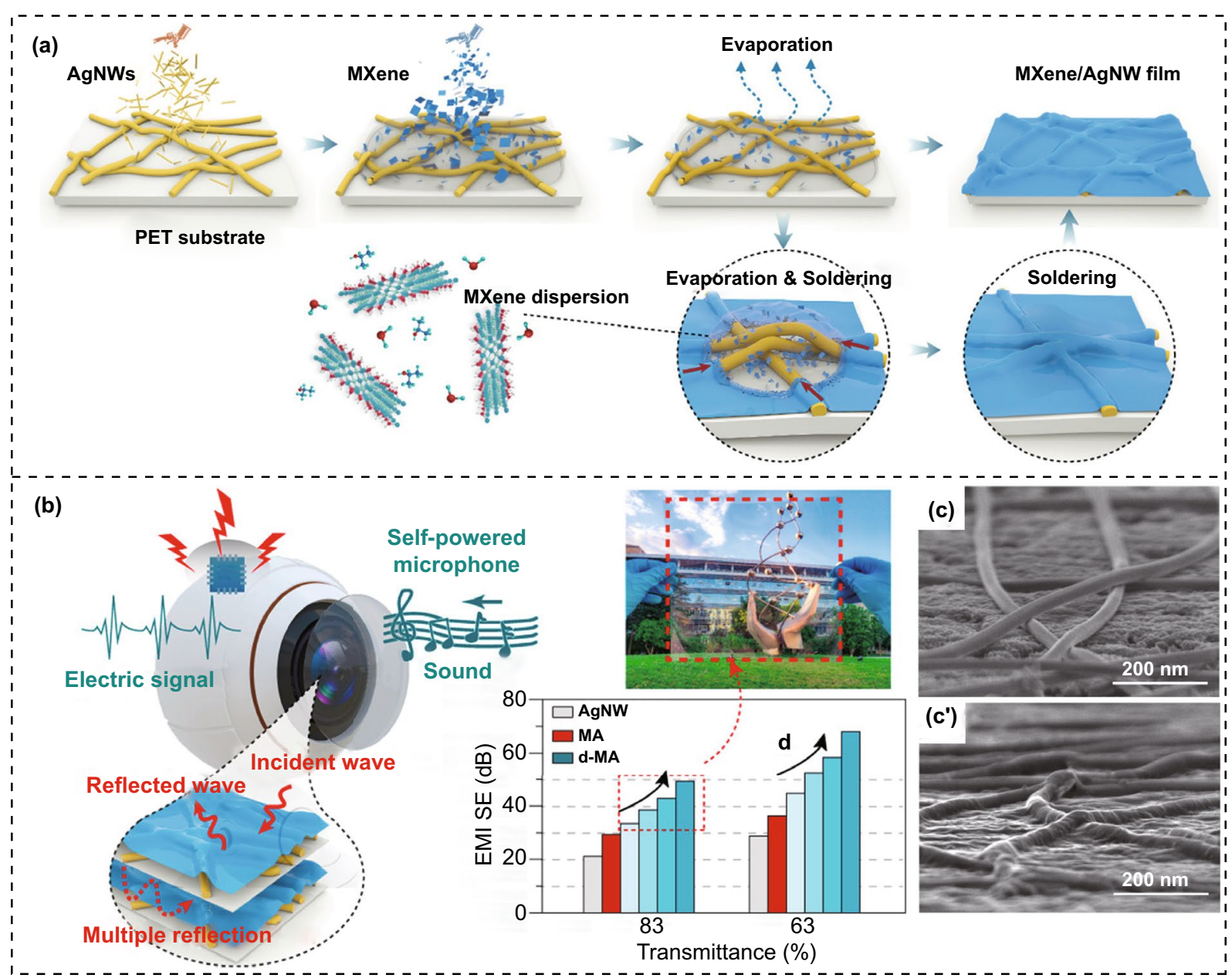

Fig. 13 a Schematic illustrating the fabrication, b EMI SE, and c SEM images of MXene/AgNW/PET composite films [140]. Copyright @ 2020 American Chemical Society

freeze-drying technique, and obtained the thermally reduced CTA (TCTA)/epoxy composites after the thermal reductionvacuum-assisted impregnation (Fig. 14c). The results show that the obtained composites have the complete and efficient three-dimensional conductive network and the low percolation threshold. When TCTA fraction is 1.38 vol\%, the radial $\sigma$ and axial EMI SE of composites are $1672 \mathrm{~S}$ $\mathrm{m}^{-1}$ and $74 \mathrm{~dB}$, respectively, which are much higher than those of epoxy composites prepared by the direct blending method with the same TCTA content. The above researches show that the multiple reflection ability of the composites for electromagnetic waves can be improved by pre-constructing a stable three-dimensional conductive network skeleton in the resin matrix, which in turn enhances the EMI shielding performance of the composites. However, the preconstruction of a three-dimensional conductive network skeleton in the resin matrix also faces some problems, such as poor interfacial compatibility between the three-dimensional skeleton structure and the resin matrix, and the continuous phase of the fillers hinders the continuous phase structure of the resin matrix. These problems eventually lead to the weak mechanical strength of the composites [108, 151, 152].

\section{Conclusions and Outlook}

This review first discusses the key concepts, loss mechanisms and test methods of EMI shielding. Then, the current development status of EMI shielding materials is totally summarized, and the research progress of polymer matrix EMI shielding composites with different structures is detailedly illustrated, in which their preparation methods 


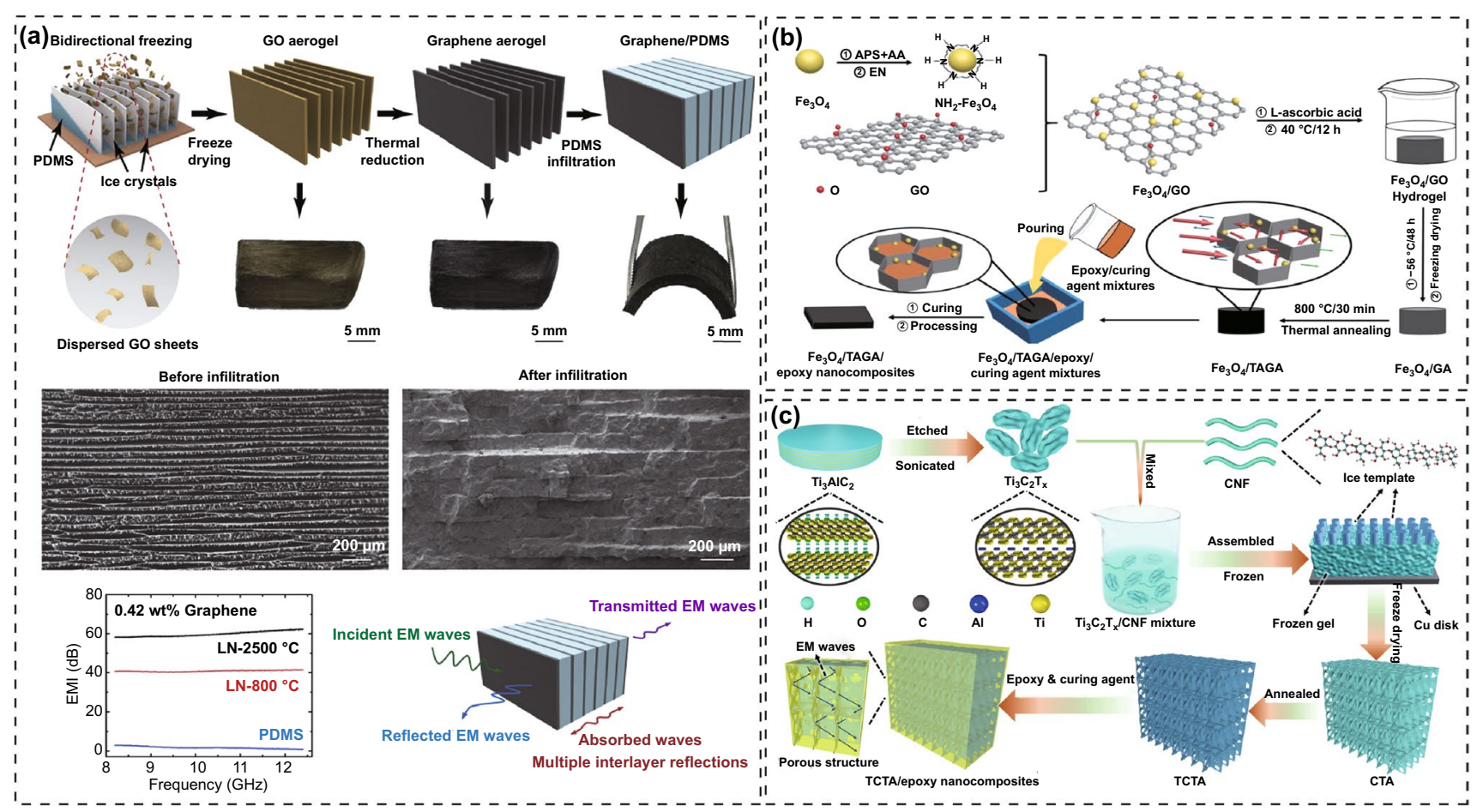

Fig. 14 Schematic illustrating the fabrication, SEM images and EMI SE of a graphene/PDMS, $\mathbf{b} \mathrm{Fe}_{3} \mathrm{O}_{4} / \mathrm{TAGA} / \mathrm{epoxy}$, and $\mathbf{c}$ TCTA/epoxy composites $[146,149,150]$. Copyright $@ 2019$ Elsevier. Copyright $@ 2018$ Elsevier

and corresponding evaluations are highlighted. It is worth noting that the purpose of the preparation methods for all polymer matrix EMI shielding composites with different structures is to build more complete conductive networks and more conductive-insulating interfaces, thereby achieving stronger polarization loss and conduction loss. Although a series of favorable advances have been made in the preparation of polymer matrix EMI shielding composites, there are still many problems. The details are summarized as follows:

(1) Although the homogeneous polymer matrix EMI shielding composites are simple to process, they require a high content of conductive fillers to build an effective conductive network in the polymer matrix, and to ensure that their EMI SE is higher than the industrial application standard of $20 \mathrm{~dB}$. However, the high content of conductive fillers will cause the decrease of mechanical properties and processing difficulties. The homogeneous polymer matrix EMI shielding composites are suitable for applications where the EMI shielding performance requirement is not high, while the mass-production and application are needed.

(2) The conductive fillers in the segregated polymer matrix EMI shielding composites are confined in the interfaces of the polymer micro-zones. The probability of interlap between the conductive fillers is significantly increased, thereby enhancing the EMI shielding performance of the composites. However, the conductive fillers form a single continuous network structure inside the composites, and the polymer particles tend to exist in isolation, which will result in relatively poor mechanical properties. This type of EMI shielding composites can be applied to the non-load-bearing parts that require high EMI shielding performances.

(3) The porous polymer matrix EMI shielding composites have the advantages of low density and good toughness. However, the polymer matrix used for the preparation of porous composites is mostly concentrated in PU, MS, PDMS, WPU, etc., which have poor heat resistance and mechanical strength. These problems limit the applications of porous composites in high-density and high-integration electronic components. As a representative of lightweight EMI shielding materials, they have great potentials for sandwich parts in areas of aircraft, military engineering and automobile industry.

(4) The layered polymer matrix EMI shielding composites can induce multiple reflections of electromagnetic waves between the internal layers due to unique stratified structure. However, the layered polymer matrix 
EMI shielding composites prepared based on vacuum filtration, layered coating, and polymer-assisted methods have weak interface connection strength and are time-consuming. The ultra-thin structure makes the layered polymer matrix EMI shielding composites gain widespread attention in the fields of visual shielding windows, microelectronic devices and electronic communication equipment.

(5) The preformed polymer matrix EMI shielding composites have the advantages such as low content of conductive fillers, high overlap efficiency of the conductive network and excellent EMI shielding performance. However, a series of preformed polymer matrix EMI shielding composites developed based on freeze-drying, hydrothermal, and CVD methods are facing problems such as scarcity of candidate conductive fillers, harsh preparation conditions and long reaction cycles. This type of EMI shielding composites is expected to be used in small-scale equipment components that require superior EMI shielding performance.

Therefore, the development of next-generation highperformance polymer matrix EMI shielding composites based on the reasonable structural design and new preparation methods has become a key research direction, which is necessary to promote the full replacement of metallic EMI shielding materials. It is believed that in the near future, polymer matrix EMI shielding composites will be more widely and comprehensively applied in various fields including aerospace, automobile manufacturing, artificial intelligence and precision instruments.

Acknowledgements The authors are grateful for the support and funding from the Foundation of National Natural Science Foundation of China (51903145 and 51973173); Natural Science Basic Research Plan for Distinguished Young Scholars in Shaanxi Province of China (2019JC-11); Fundamental Research Funds for the Central Universities (D5000210627); This work is also financially supported by Polymer Electromagnetic Functional Materials Innovation Team of Shaanxi Sanqin Scholars.

Open Access This article is licensed under a Creative Commons Attribution 4.0 International License, which permits use, sharing, adaptation, distribution and reproduction in any medium or format, as long as you give appropriate credit to the original author(s) and the source, provide a link to the Creative Commons licence, and indicate if changes were made. The images or other third party material in this article are included in the article's Creative Commons licence, unless indicated otherwise in a credit line to the material. If material is not included in the article's Creative Commons licence and your intended use is not permitted by statutory regulation or exceeds the permitted use, you will need to obtain permission directly from the copyright holder. To view a copy of this licence, visit http://creativecommons.org/licenses/by/4.0/.

\section{References}

1. JM Thomassin C Jerome T Pardoen C Bailly I Huynen 2013 Polymer/carbon based composites as electromagnetic interference (EMI) shielding materials Mater. Sci. Eng. R-Rep. 74 211232 https://doi.org/10.1016/j.mser.2013.06.001

2. F Shahzad M Alhabeb CB Hatter B Anasori SM Hong 2016 Electromagnetic interference shielding with 2D transition metal carbides (MXenes) Science 35311371140 https://doi. org/10.1126/science.aag2421

3. H Abbasi M Antunes JI Velasco 2019 Recent advances in carbon-based polymer nanocomposites for electromagnetic interference shielding Prog. Mater. Sci. 103319373 https:// doi.org/10.1016/j.pmatsci.2019.02.003

4. P Song B Liu C Liang K Ruan H Qiu 2021 Lightweight, flexible cellulose-derived carbon aerogel@ reduced graphene oxide/PDMS composites with outstanding EMI shielding performances and excellent thermal conductivities Nano-Micro Lett. 1391 https://doi.org/10.1007/s40820-021-00624-4

5. S Liu J Liu X Dong Y Duan 2013 Electromagnetic Wave Shielding and Absorbing Materials 2 Chemical Industry Press Beijing 5459

6. R Yang X Gui L Yao Q Hu L Yang 2021 Ultrathin, lightweight, and flexible CNT buckypaper enhanced using MXenes for electromagnetic interference shielding Nano-Micro Lett. 1366 https://doi.org/10.1007/ s40820-021-00597-4

7. P Kumar UN Maiti A Sikdar TK Das A Kumar 2019 Recent advances in polymer and polymer composites for electromagnetic interference shielding: review and future prospects Polym. Rev. 59687738 https://doi.org/10.1080/15583724. 2019.1625058

8. L Wu F Wu Q Sun J Shi A Xie 2021 A TTF-TCNQ complex: an organic charge-transfer system with extraordinary electromagnetic response behavior J. Mater. Chem. C 933163323 https://doi.org/10.1039/D0TC05230B

9. DW Jiang V Murugadoss Y Wang J Lin T Ding 2019 Electromagnetic interference shielding polymers and nanocomposites: a review Polym. Rev. 59280337 https://doi.org/10. 1080/15583724.2018.1546737

10. M Guo J Huang Y Deng H Shen Y Ma 2015 pH-Responsive cyanine-grafted graphene oxide for fluorescence resonance energy transfer-enhanced photothermal therapy Adv. Funct. Mater. 255967 https://doi.org/10.1002/adfm.201402762

11. L. Wang, Z. Ma, L. Chen, Y. Zhang, D. Cao, et al., Polymerbased EMI shielding composites with 3D conductive networks: a mini-review. SusMat (2021) doi:https://doi.org/10. $1002 /$ sus 2.21 
12. A Iqbal P Sambyal CM Koo 2020 2D MXenes for electromagnetic shielding: a review Adv. Funct. Mater. 30 2000883 https://doi.org/10.1002/adfm.202000883

13. X Yang S Fan Y Li Y Guo Y Li 2020 Synchronously improved electromagnetic interference shielding and thermal conductivity for epoxy nanocomposites by constructing 3D copper nanowires/thermally annealed graphene aerogel framework Compos. A-Appl. S. 128105670 https://doi.org/ 10.1016/j.compositesa.2019.105670

14. AK Singh A Shishkin T Koppel N Gupta 2018 A review of porous lightweight composite materials for electromagnetic interference shielding Compos. B-Eng. 149188197 https:// doi.org/10.1016/j.compositesb.2018.05.027

15. Y Guo L Pan X Yang K Ruan Y Han 2019 Simultaneous improvement of thermal conductivities and electromagnetic interference shielding performances in polystyrene composites via constructing interconnection oriented networks based on electrospinning technology Compos. A Appl. S. $124105484 \mathrm{https} / / /$ doi.org/10.1016/j.compositesa.2019. 105484

16. F Pan Z Liu B Deng Y Dong X Zhu 2021 Lotus leaf-derived gradient hierarchical porous $\mathrm{C} / \mathrm{MoS}_{2}$ morphology genetic composites with wideband and tunable electromagnetic absorption performance Nano-Micro Lett. 1343 https://doi. org/10.1007/s40820-020-00568-1

17. P Song B Liu H Qiu X Shi D Cao 2021 MXenes for polymer matrix electromagnetic interference shielding composites: a review Compos. Commun. 24100653 https://doi.org/10. 1016/j.coco.2021.100653

18. Y Zhu J Liu T Guo JJ Wang X Tang 2021 Multifunctional $\mathrm{Ti}_{3} \mathrm{C}_{2} \mathrm{~T}_{\mathrm{x}}$ MXene composite hydrogels with strain sensitivity toward absorption-dominated electromagnetic-interference shielding ACS Nano 1514651474 https://doi.org/10.1021/ acsnano.0c08830

19. Y Zhang K Ruan X Shi H Qiu Y Pan $2021 \mathrm{Ti}_{3} \mathrm{C}_{2} \mathrm{~T}_{\mathrm{x}} / \mathrm{rGO}$ porous composite films with superior electromagnetic interference shielding performances Carbon $175271280 \mathrm{https}$ :// doi.org/10.1016/j.carbon.2020.12.084

20. S Sankaran K Deshmukh MB Ahamed SKK Pasha 2018 Recent advances in electromagnetic interference shielding properties of metal and carbon filler reinforced flexible polymer composites: a review Compos. A Appl. S. 1144971 https://doi.org/10.1016/j.compositesa.2018.08.006

21. E Pakdel J Wang S Kashi L Sun X Wang 2020 Advances in photocatalytic self-cleaning, superhydrophobic and electromagnetic interference shielding textile treatments Adv. Colloid Interface Sci. 277102116 https://doi.org/10.1016/j.cis. 2020.102116

22. A Nazir HJ Yu L Wang M Haroon RS Ullah 2018 Recent progress in the modification of carbon materials and their application in composites for electromagnetic interference shielding J. Mater. Sci. 5386998719 https://doi.org/10.1007/ s10853-018-2122-x

23. Y Jiao S Cheng F Wu X Pan A Xie 2021 MOF-Guest complex derived $\mathrm{Cu} / \mathrm{C}$ nanocomposites with multiple heterogeneous interfaces for excellent electromagnetic waves absorption Compos. B Eng. 211108643 https://doi.org/10. 1016/j.compositesb.2021.108643

24. S Geetha KKS Kumar CRK Rao M Vijayan DC Trivedi 2009 EMI shielding: methods and materials: a review J. Appl. Polym. Sci. 11220732086 https://doi.org/10.1002/ app. 29812

25. S Cheng A Xie X Pan K Zhang C Zhang 2021 Modulating surficial oxygen vacancy of the $\mathrm{VO}_{2}$ nanostructure to boost its electromagnetic absorption performance J. Mater. Chem. C https://doi.org/10.1039/D1TC02136B

26. W Huang X Zhang Y Zhao J Zhang P Liu 2020 Hollow $\mathrm{N}$-doped carbon polyhedra embedded $\mathrm{Co}$ and $\mathrm{Mo}_{2} \mathrm{C}$ nanoparticles for high-efficiency and wideband microwave absorption Carbon 1671930 https://doi.org/10.1016/j.carbon.2020.05. 073

27. P Song H Qiu L Wang X Liu Y Zhang 2020 Honeycomb structural rGO-MXene/epoxy nanocomposites for superior electromagnetic interference shielding performance Sustain. Mater. Technol. 24 e00153 https://doi.org/10.1016/j.susmat. 2020.e00153

28. J Zhao Y Lu W Ye L Wang B Liu 2019 Enhanced waveabsorbing performances of silicone rubber composites by incorporating $\mathrm{C}-\mathrm{SnO}_{2}-\mathrm{MWCNT}$ absorbent with ternary heterostructure Ceram. Int. 452028220289 https://doi.org/10. 1016/j.ceramint.2019.06.302

29. N Bagotia V Choudhary DK Sharma 2018 A review on the mechanical, electrical and EMI shielding properties of carbon nanotubes and graphene reinforced polycarbonate nanocomposites Polym. Adv. Technol. 2915471567 https://doi.org/ 10.1002/pat.4277

30. Z Zeng F Jiang Y Yue D Han L Lin 2020 Flexible and ultrathin waterproof cellular membranes based on high-conjunction metal-wrapped polymer nanofibers for electromagnetic interference shielding Adv. Mater. 321908496 https:// doi.org/10.1002/adma.201908496

31. Q Song B Chen Z Zhou C Lu 2021 Flexible, stretchable and magnetic $\mathrm{Fe}_{3} \mathrm{O}_{4} @ \mathrm{Ti}_{3} \mathrm{C}_{2} \mathrm{~T}_{\mathrm{x}}$ /elastomer with supramolecular interfacial crosslinking for enhancing mechanical and electromagnetic interference shielding performance Sci. China Mater. 6414371448 https://doi.org/10.1007/ s40843-020-1539-2

32. HK Choi A Lee M Park DS Lee S Bae 2021 Hierarchical porous film with layer-by-layer assembly of $2 \mathrm{D}$ copper nanosheets for ultimate electromagnetic interference shielding ACS Nano 15829839 https://doi.org/10.1021/acsnano. 0c07352

33. J Park JW Lee HJ Choi WG Jang TS Kim 2019 Electromagnetic interference shielding effectiveness of sputtered NiFe/ $\mathrm{Cu}$ multi-layer thin film at high frequencies Thin Solid Films 677130136 https://doi.org/10.1016/j.tsf.2019.03.015

34. P Sambyal SJ Noh JP Hong WN Kim A Iqbal 2019 FeSiAl/ metal core shell hybrid composite with high-performance electromagnetic interference shielding Compos. Sci. Technol. 1726673 https://doi.org/10.1016/j.compscitech.2019.01.007

35. K Song FS Pan XH Chen ZH Zhang AT Tang 2015 Effect of texture on the electromagnetic shielding property of 
magnesium alloy Mater. Lett. 1577376 https://doi.org/10. 1016/j.matlet.2015.05.017

36. Z Jia M Zhang B Liu F Wang G Wei 2020 Graphene foams for electromagnetic interference shielding: a review ACS Appl. Nano Mater. 361406155 https://doi.org/10.1021/ acsanm.0c00835

37. SS Pradhan L Unnikrishnan S Mohanty SK Nayak 2020 Thermally conducting polymer composites with EMI shielding: a review J. Electron. Mater. 4917491764 https://doi.org/10. 1007/s11664-019-07908-x

38. J Zhao J Zhang L Wang S Lyu W Ye 2020 Fabrication and investigation on ternary heterogeneous MWCNT@ $\mathrm{TiO}_{2}-\mathrm{C}$ fillers and their silicone rubber wave-absorbing composites Compos. A Appl. S. 129105714 https://doi.org/10.1016/j. compositesa.2019.105714

39. A Massa P Rocca G Oliveri 2015 Compressive sensing in electromagnetics: a review IEEE Antenn. Propag. M. 57224 $238 \mathrm{https}: / /$ doi.org/10.1109/MAP.2015.2397092

40. A Sheng W Ren Y Yang D-X Yan H Duan 2020 Multilayer WPU conductive composites with controllable electromagnetic gradient for absorption-dominated electromagnetic interference shielding Compos. A Appl. S. 129105692 https://doi.org/10.1016/j.compositesa.2019.105692

41. J-B Park H Rho A-N Cha H Bae SH Lee 2020 Transparent carbon nanotube web structures with $\mathrm{Ni}-\mathrm{Pd}$ nanoparticles for electromagnetic interference (EMI) shielding of advanced display devices Appl. Surf. Sci. 516145745 https://doi.org/ 10.1016/j.apsusc.2020.145745

42. A Iqbal F Shahzad K Hantanasirisakul M-K Kim J Kwon 2020 Anomalous absorption of electromagnetic waves by $2 \mathrm{D}$ transition metal carbonitride $\mathrm{Ti}_{3} \mathrm{CNT}_{\mathrm{x}}$ (MXene) Science 369 446450 https://doi.org/10.1126/science.aba7977

43. Y Fei M Liang L Yan Y Chen H Zou 2020 Co/C@ cellulose nanofiber aerogel derived from metal-organic frameworks for highly efficient electromagnetic interference shielding Chem. Eng. J. 392124815 https://doi.org/10.1016/j.cej.2020.124815

44. F Ren DP Song Z Li LC Jia YC Zhao 2018 Synergistic effect of graphene nanosheets and carbonyl iron-nickel alloy hybrid filler on electromagnetic interference shielding and thermal conductivity of cyanate ester composites J. Mater. Chem. C 614761486 https://doi.org/10.1039/C7TC05213H

45. J Luo L Huo L Wang X Huang J Li 2020 Superhydrophobic and multi-responsive fabric composite with excellent electrophoto-thermal effect and electromagnetic interference shielding performance Chem. Eng. J. 391123537 https://doi.org/ 10.1016/j.cej.2019.123537

46. QH Liu Q Cao H Bi CY Liang KP Yuan2016CoNi@SiO $@$ $\mathrm{TiO}_{2}$ and $\mathrm{CoNi} @$ Air@ $\mathrm{TiO}_{2}$ Microspheres with strong wideband microwave absorption Adv. Mater. 28486490 https:// doi.org/10.1002/adma.201503149

47. XH Liang ZM Man B Quan J Zheng WH Gu 2020 Environment-stable $\mathrm{Co}_{\mathrm{x}} \mathrm{Ni}_{\mathrm{y}}$ encapsulation in stacked porous carbon nanosheets for enhanced microwave absorption Nano-Micro Lett. 12102 https://doi.org/10.1007/s40820-020-00432-2

48. DQ Zhang YF Xiong JY Cheng JX Chai TT Liu 2020 Synergetic dielectric loss and magnetic loss towards superior microwave absorption through hybridization of few-layer $\mathrm{WS}_{2}$ nanosheets with $\mathrm{NiO}$ nanoparticles Sci. Bull. 65138 146 https://doi.org/10.1016/j.scib.2019.10.011

49. H Shi C Liu Q Jiang J Xu 2015 Effective approaches to improve the electrical conductivity of PEDOT:PSS: a review Adv. Electron. Mater. 11500017 https://doi.org/10.1002/ aelm.201500017

50. X Zhang N Zhao C He 2020 The superior mechanical and physical properties of nanocarbon reinforced bulk composites achieved by architecture design: a review Prog. Mater. Sci. 113100672 https://doi.org/10.1016/j.pmatsci.2020.100672

51. J Zhao J Zhang L Wang J Li T Feng 2020 Superior waveabsorbing performances of silicone rubber composites via introducing covalently bonded $\mathrm{SnO}_{2} @$ MWCNT absorbent with encapsulation structure Compos. Commun. 22100486 https://doi.org/10.1016/j.coco.2020.100486

52. H Liu Q Li S Zhang R Yin X Liu 2018 Electrically conductive polymer composites for smart flexible strain sensors: a critical review J. Mater. Chem. C 61212112141 https://doi. org/10.1039/C8TC04079F

53. C Liang H Qiu P Song X Shi J Kong 2020 Ultra-light MXene aerogel/wood-derived porous carbon composites with walllike "mortar/brick" structures for electromagnetic interference shielding Sci. Bull. 65616622 https://doi.org/10.1016/j. scib.2020.02.009

54. L Wang X Shi J Zhang Y Zhang J Gu 2020 Lightweight and robust $\mathrm{rGO}$ /sugarcane derived hybrid carbon foams with outstanding EMI shielding performance J. Mater. Sci. Technol. 52119126 https://doi.org/10.1016/j.jmst.2020.03.029

55. X Wang C Yang J Jin X Li Q Cheng 2018 High-performance stretchable supercapacitors based on intrinsically stretchable acrylate rubber/MWCNTs@ conductive polymer composite electrodes J. Mater. Chem. A 644324442 https://doi.org/10. 1039/C7TA11173H

56. M Qiu Y Zhang B Wen 2018 Facile synthesis of polyaniline nanostructures with effective electromagnetic interference shielding performance J. Mater. Sci. Mater. El. 2910437 10444 https://doi.org/10.1007/s10854-018-9100-6

57. D Mueller CR Rambo DOS Recouvreux LM Porto GMO Barra 2011 Chemical in situ polymerization of polypyrrole on bacterial cellulose nanofibers Synth. Met. 161106111 https://doi.org/10.1016/j.synthmet.2010.11.005

58. Y Wang C Zhu R Pfattner H Yan L Jin 2017 A highly stretchable, transparent, and conductive polymer Sci. Adv. 3 e1602076 https://doi.org/10.1126/sciadv.1602076

59. P Han X Zhang J Qiao 2016 Intrinsically conductive polymer fibers from thermoplastic trans-1,4-polyisoprene Langmuir 3249044908 https://doi.org/10.1021/acs.langmuir.6b01333

60. J Li A Wang J Qin H Zhang Z Ma 2021 Lightweight polymethacrylimide@copper/nickel composite foams for electromagnetic shielding and monopole antennas Compos. A Appl. S. 140106144 https://doi.org/10.1016/j.compositesa.2020. 106144

61. C Ma WT Cao W Zhang MG Ma WM Sun 2021 Wearable, ultrathin and transparent bacterial celluloses/MXene film with Janus structure and excellent mechanical property for 
electromagnetic interference shielding Chem. Eng. J. 403 126438 https://doi.org/10.1016/j.cej.2020.126438

62. L Li S Zhao X-J Luo H-B Zhang Z-Z Yu 2021 Smart MXenebased Janus films with multi-responsive actuation capability and high electromagnetic interference shielding performances Carbon 175594602 https://doi.org/10.1016/j.carbon.2020. 10.090

63. C Jiang D Tan Q Li J Huang J Bu 2021 High-performance and reliable silver nanotube networks for efficient and largescale transparent electromagnetic interference shielding ACS Appl. Mater. Interfaces 131552515535 https://doi.org/10. 1021/acsami.1c00590

64. DDL Chung 2000 Materials for electromagnetic interference shielding J. Mater. Eng. Perform. 9350354 https://doi.org/ 10.1016/j.matchemphys.2020.123587

65. J-C Shu W-Q Cao M-S Cao 2021 Diverse metal-organic framework architectures for electromagnetic absorbers and shielding Adv. Funct. Mater. 312100470 https://doi.org/10. 1002/adfm.202100470

66. K Pang X Liu Y Liu Y Chen Z Xu 2021 Highly conductive graphene film with high-temperature stability for electromagnetic interference shielding Carbon 179202208 https://doi. org/10.1016/j.carbon.2021.04.027

67. J Liang Y Wang Y Huang Y Ma Z Liu 2009 Electromagnetic interference shielding of graphene/epoxy composites Carbon 47922925 https://doi.org/10.1016/j.carbon.2008.12.038

68. MX Li K Yang WG Zhu JH Shen J Rollinson 2020 Coppercoated reduced graphene oxide fiber mesh-polymer composite films for electromagnetic interference shielding ACS Appl. Nano Mater. 355655574 https://doi.org/10.1021/ acsanm.0c00843

69. C Liang K Ruan Y Zhang J Gu 2020 Multifunctional flexible electromagnetic interference shielding silver nanowires/ cellulose films with excellent thermal management and Joule heating performances ACS Appl. Mater. Interfaces 1218023 18031 https://doi.org/10.1021/acsami.0c04482

70. C Liang P Song H Gu C Ma Y Guo 2017 Nanopolydopamine coupled fluorescent nanozinc oxide reinforced epoxy nanocomposites Compos. A Appl. S. 102126136 https://doi.org/ 10.1016/j.compositesa.2017.07.030

71. DDL Chung 2019 A review of multifunctional polymermatrix structural composites Compos. B Eng. 160644660 https://doi.org/10.1016/j.compositesb.2018.12.117

72. SA Umoren MM Solomon 2019 Protective polymeric films for industrial substrates: a critical review on past and recent applications with conducting polymers and polymer composites/nanocomposites Prog. Mater. Sci. 104380450 https:// doi.org/10.1016/j.pmatsci.2019.04.002

73. L Wang H Qiu C Liang P Song Y Han 2019 Electromagnetic interference shielding MWCNT-Fe $\mathrm{O}_{4} @ \mathrm{Ag}$ /epoxy nanocomposites with satisfactory thermal conductivity and high thermal stability Carbon 141506514 https://doi.org/10.1016/j. carbon.2018.10.003

74. L Wang L Chen P Song C Liang Y Lu 2019 Fabrication on the annealed $\mathrm{Ti}_{3} \mathrm{C}_{2} \mathrm{~T}_{\mathrm{x}}$ MXene/Epoxy nanocomposites for electromagnetic interference shielding application Compos.
B Eng. 171111118 https://doi.org/10.1016/j.compositesb. 2019.04.050

75. Q He R Chen S Li Z Wang F Wen 2021 Excellent thermally conducting modified graphite nanoplatelets and MWCNTs/ poly(phenylene sulfone) composites for high-performance electromagnetic interference shielding effectiveness Compos. A Appl. S. 143106280 https://doi.org/10.1016/j. compositesa.2021.106280

76. S Kwon R Ma U Kim HR Choi S Baik 2014 Flexible electromagnetic interference shields made of silver flakes, carbon nanotubes and nitrile butadiene rubber Carbon 68118 124 https://doi.org/10.1016/j.carbon.2013.10.070

77. MH Al-Saleh WH Saadeh U Sundararaj 2013 EMI shielding effectiveness of carbon based nanostructured polymeric materials: a comparative study Carbon 60146156 https:// doi.org/10.1016/j.carbon.2013.04.008

78. Y Park K-J Baeg C Kim 2019 Solution-processed nonvolatile organic transistor memory based on semiconductor blends ACS Appl. Mater. Interfaces 1183278336 https:// doi.org/10.1021/acsami.8b20571

79. T Leydecker MA Squillaci F Liscio E Orgiu P Samori 2019 Controlling ambipolar transport and voltage inversion in solution-processed thin-film devices through polymer blending Chem. Mater. 3164916498 https://doi.org/10. 1021/acs.chemmater.8b04819

80. H Wang K Zheng X Zhang X Ding Z Zhang 2016 3D network porous polymeric composites with outstanding electromagnetic interference shielding Compos. Sci. Technol. 1252229 https://doi.org/10.1016/j.compscitech.2016.01. 007

81. NC Das D Khastgir TK Chaki A Chakraborty 2000 Electromagnetic interference shielding effectiveness of carbon black and carbon fibre filled EVA and NR based composites Compos. A Appl. S. 3110691081 https://doi.org/10.1016/ S1359-835X(00)00064-6

82. H Duan M Zhao Y Yang G Zhao Y Liu 2018 Flexible and conductive PP/EPDM/Ni coated glass fiber composite for efficient electromagnetic interference shielding J. Mater. Sci. Mater. El. 291032910336 https://doi.org/10.1007/ s10854-018-9089-x

83. C Liang C Hu Y Zheng K Yan X Zhu 2018 Modification of isotactic polypropylene by silica nanocapsules via melt blending method Polym. Compos. 39762769 https://doi.org/ 10.1002/pc.23995

84. S Deng H Bai Z Liu Q Zhang Q Fu 2019 Toward supertough and heat-resistant stereocomplex-type polylactide/elastomer blends with impressive melt stability via in situ formation of graft copolymer during one-pot reactive melt blending Macromolecules $5217181730 \mathrm{https} / / /$ doi.org/10.1021/acs.macro mol.8b02626

85. Y Wang FQ Gu LJ Ni K Liang K Marcus 2017 Easily fabricated and lightweight PPy/PDA/AgNW composites for excellent electromagnetic interference shielding Nanoscale 91831818325 https://doi.org/10.1039/C7NR05951E

86. P Saini V Choudhary BP Singh RB Mathur SK Dhawan 2009 Polyaniline-MWCNT nanocomposites for microwave 
absorption and EMI shielding Mater. Chem. Phys. 113919 926 https://doi.org/10.1016/j.matchemphys.2008.08.065

87. J Yun H-I Kim 2011 Electromagnetic interference shielding effects of polyaniline-coated multi-wall carbon nanotubes/ maghemite nanocomposites Polym. Bull. 68561573 https:// doi.org/10.1007/s00289-011-0651-4

88. J Loste JM Lopez-Cuesta L Billon H Garay M Save 2019 Transparent polymer nanocomposites: an overview on their synthesis and advanced properties Prog. Polym. Sci. 89133 158 https://doi.org/10.1016/j.progpolymsci.2018.10.003

89. C Harito DV Bavykin B Yuliarto HK Dipojono FC Walsh 2019 Polymer nanocomposites having a high filler content: synthesis, structures, properties, and applications Nanoscale 1146534682 https://doi.org/10.1039/C9NR00117D

90. Y Guo X Yang K Ruan J Kong M Dong 2019 Reduced graphene oxide heterostructured silver nanoparticles significantly enhanced thermal conductivities in hot-pressed electrospun polyimide nanocomposites ACS Appl. Mater. Interfaces 112546525473 https://doi.org/10.1021/acsami. 9b10161

91. D-X Yan P-G Ren H Pang Q Fu M-B Yang 2012 Efficient electromagnetic interference shielding of lightweight graphene/polystyrene composite J. Mater. Chem. 2218772 18774 https://doi.org/10.1039/C2JM32692B

92. LC Jia DX Yan X Jiang H Pang JF Gao 2018 Synergistic effect of graphite and carbon nanotubes on improved electromagnetic interference shielding performance in segregated composites Ind. Eng. Chem. Res. 571192911938 https://doi. org/10.1021/acs.iecr.8b03238

93. Z Lv CL Jia X Ji DX Yan J Lei 2018 Repeatable, room-temperature-processed baroplastic-carbon nanotube composites for electromagnetic interference shielding J. Mater. Chem. C 61295512964 https://doi.org/10.1039/C8TC04348E

94. L Vovchenko L Matzui V Oliynyk V Launets Y Mamunya 2018 Nanocarbon/polyethylene composites with segregated conductive network for electromagnetic interference shielding Mol. Cryst. Liq. Cryst. 672186198 https://doi.org/10. 1080/15421406.2018.1555349

95. C-H Cui D-X Yan H Pang L-C Jia Y Bao 2016 Towards efficient electromagnetic interference shielding performance for polyethylene composites by structuring segregated carbon black/graphite networks Chin. J. Polym. Sci. 3414901499 https://doi.org/10.1007/s10118-016-1849-6

96. D-X Yan H Pang B Li R Vajtai L Xu 2015 Structured reduced graphene oxide/polymer composites for ultra-efficient electromagnetic interference shielding Adv. Funct. Mater. 25559 566 https://doi.org/10.1002/adfm.201403809

97. RH Sun HB Zhang J Liu X Xie R Yang 2017 Highly conductive transition metal carbide/carbonitride(MXene)@ polystyrene nanocomposites fabricated by electrostatic assembly for highly efficient electromagnetic interference shielding Adv. Funct. Mater. 271702807 https://doi.org/10.1002/adfm. 201702807

98. Y Zhan J Wang K Zhang Y Li Y Meng 2018 Fabrication of a flexible electromagnetic interference shielding $\mathrm{Fe}_{3} \mathrm{O}_{4} @$ reduced graphene oxide/natural rubber composite with segregated network Chem. Eng. J. 344184193 https:// doi.org/10.1016/j.cej.2018.03.085

99. C Liang P Song H Qiu Y Huangfu Y Lu 2019 Superior electromagnetic interference shielding performances of epoxy composites by introducing highly aligned reduced graphene oxide films Compos. A Appl. S. 124105512 https://doi.org/10.1016/j.compositesa.2019.105512

100. Z Ma A Wei Y Li L Shao H Zhang 2021 Lightweight, flexible and highly sensitive segregated microcellular nanocomposite piezoresistive sensors for human motion detection Compos. Sci. Technol. 203108571 https://doi.org/10. 1016/j.compscitech.2020.108571

101. LY Zhang M Liu S Roy EK Chu KY See 2016 Phthalonitrile-based carbon foam with high specific mechanical strength and superior electromagnetic interference shielding performance ACS Appl. Mater. Interfaces 874227430 https://doi.org/10.1021/acsami.5b12072

102. B Shen Y Li WT Zhai WG Zheng 2016 Compressible graphene-coated polymer foams with ultralow density for adjustable electromagnetic interference (EMI) shielding ACS Appl. Mater. Interfaces 880508057 https://doi.org/ 10.1021/acsami.5b11715

103. ZM Fan DL Wang Y Yuan YS Wang ZJ Cheng 2020 A lightweight and conductive MXene/graphene hybrid foam for superior electromagnetic interference shielding Chem. Eng. J. 381122696 https://doi.org/10.1016/j.cej. 2019. 122696

104. H Zhang G Zhang Q Gao M Tang Z Ma 2020 Multifunctional microcellular PVDF/Ni-chains composite foams with enhanced electromagnetic interference shielding and superior thermal insulation performance Chem. Eng. J. 379122304 https://doi.org/10.1016/j.cej.2019.122304

105. V Eswaraiah V Sankaranarayanan S Ramaprabhu 2011 Functionalized graphene-PVDF foam composites for EMI shielding Macromol. Mater. Eng. 296894898 https://doi.org/10. 1002/mame.201100035

106. HM Zhang GC Zhang M Tang LS Zhou JT Li 2018 Synergistic effect of carbon nanotube and graphene nanoplates on the mechanical, electrical and electromagnetic interference shielding properties of polymer composites and polymer composite foams Chem. Eng. J. 353381393 https://doi.org/ 10.1016/j.cej.2018.07.144

107. X Fan G Zhang Q Gao J Li Z Shang 2019 Highly expansive, thermally insulating epoxy/Ag nanosheet composite foam for electromagnetic interference shielding Chem. Eng. J. 372191 202 https://doi.org/10.1016/j.cej.2019.04.069

108. L Wang H Qiu P Song Y Zhang Y Lu 2019 3D $\mathrm{Ti}_{3} \mathrm{C}_{2} \mathrm{~T}_{\mathrm{x}}$ MXene/C hybrid foam/epoxy nanocomposites with superior electromagnetic interference shielding performances and robust mechanical properties Compos. A Appl. S. 123293 300 https://doi.org/10.1016/j.compositesa.2019.05.030

109. Z Zeng H Jin M Chen W Li L Zhou 2016 Lightweight and anisotropic porous MWCNT/WPU composites for ultrahigh performance electromagnetic interference shielding Adv. Funct. Mater. 26303310 https://doi.org/10.1002/adfm.20150 3579 
110. ZH Zeng CX Wang YF Zhang PY Wang SIS Shahabadi 2018 Ultralight and highly elastic graphene/lignin-derived carbon nanocomposite aerogels with ultrahigh electromagnetic interference shielding performance ACS Appl. Mater. Interfaces $1082058213 \mathrm{https} / / /$ doi.org/10.1021/acsami. $7 b 19427$

111. ZH Zeng TT Wu DX Han Q Ren G Siqueira 2020 Ultralight, flexible, and biomimetic nanocellulose/silver nanowire aerogels for electromagnetic interference shielding ACS Nano 14 29272938 https://doi.org/10.1021/acsnano.9b07452

112. ZH Zeng CX Wang G Siqueira DX Han A Huch 2020 Nanocellulose-MXene biomimetic aerogels with orientation-tunable electromagnetic interference shielding performance Adv. Sci. 72000979 https://doi.org/10.1002/advs.202000979

113. Z-H Zhou M-Z Li H-D Huang L Li B Yang 2020 Structuring hierarchically porous architecture in biomass-derived carbon aerogels for simultaneously achieving high electromagnetic interference shielding effectiveness and high absorption coefficient ACS Appl. Mater. Interfaces 121884018849 https:// doi.org/10.1021/acsami.0c01190

114. C Liang P Song A Ma X Shi H Gu 2019 Highly oriented three-dimensional structures of $\mathrm{Fe}_{3} \mathrm{O}_{4}$ decorated CNTs/ reduced graphene oxide foam/epoxy nanocomposites against electromagnetic pollution Compos. Sci. Technol. 181107683 https://doi.org/10.1016/j.compscitech.2019.107683

115. QW Wang HB Zhang J Liu S Zhao X Xie 2019 Multifunctional and water-resistant MXene-Decorated polyester textiles with outstanding electromagnetic interference shielding and Joule heating performances Adv. Funct. Mater. 291806819 https://doi.org/10.1002/adfm.201806819

116. S Lin J Liu Q Wang D Zu H Wang 2019 Highly robust, flexible, and large-scale 3D-Metallized sponge for high-performance electromagnetic interference shielding Adv. Mater. Technol. 5 1900761 https://doi.org/10.1002/admt.201900761

117. N Van-Tam BK Min Y Yi SJ Kim C-G Choi 2020 MXene $\left(\mathrm{Ti}_{3} \mathrm{C}_{2} \mathrm{~T}_{\mathrm{x}}\right) /$ graphene/PDMS composites for multifunctional broadband electromagnetic interference shielding skins Chem. Eng. J. 393124608 https://doi.org/10.1016/j.cej.2020. 124608

118. C Liang Y Liu Y Ruan H Qiu P Song 2020 Multifunctional sponges with flexible motion sensing and outstanding thermal insulation for superior electromagnetic interference shielding Compos. A Appl. S. 139106143 https://doi.org/10.1016/j. compositesa.2020.106143

119. T Zhou C Xu H Liu Q Wei H Wang 2020 Second time-scale synthesis of high-quality graphite films by quenching for effective electromagnetic interference shielding ACS Nano 1431213128 https://doi.org/10.1021/acsnano.9b08169

120. X Zhang X Wang Z Lei L Wang M Tian 2020 Flexible MXene-Decorated fabric with interwoven conductive networks for integrated Joule heating, electromagnetic interference shielding, and strain sensing performances ACS Appl. Mater. Interfaces 121445914467 https://doi.org/10.1021/ acsami.0c01182

121. J Liu ZS Liu HB Zhang W Chen ZF Zhao 2020 Ultrastrong and highly conductive MXene-Based films for high-performance electromagnetic interference shielding Adv. Electron. Mater. 61901094 https://doi.org/10.1002/ aelm.201901094

122. JQ Luo S Zhao HB Zhang ZM Deng LL Li 2019 Flexible, stretchable and electrically conductive MXene/natural rubber nanocomposite films for efficient electromagnetic interference shielding Compos. Sci. Technol. 182107754 https:// doi.org/10.1016/j.compscitech.2019.107754

123. Z Ma S Kang J Ma L Shao A Wei 2019 High-Performance and rapid-response electrical heaters based on ultraflexible, heat-resistant, and mechanically strong aramid nanofiber/Ag nanowire nnanocomposite papers ACS Nano 1375787590 https://doi.org/10.1021/acsnano.9b00434

124. Z Ma S Kang J Ma L Shao Y Zhang 2020 Ultraflexible and mechanically strong double-layered aramid nanofiber- $\mathrm{Ti}_{3} \mathrm{C}_{2} \mathrm{~T}_{\mathrm{x}}$ $\mathrm{MXene/silver} \mathrm{nanowire} \mathrm{nanocomposite} \mathrm{papers} \mathrm{for} \mathrm{high-per-}$ formance electromagnetic interference shielding ACS Nano 1483688382 https://doi.org/10.1021/acsnano.0c02401

125. B Zhou Z Zhang Y Li G Han Y Feng 2020 Flexible, robust, and multifunctional electromagnetic interference shielding film with alternating cellulose nanofiber and MXene layers ACS Appl. Mater. Interfaces 1248954905 https://doi.org/10. 1021/acsami.9b19768

126. YL Zhang L Wang JL Zhang P Song ZR Xiao 2019 Fabrication and investigation on the ultra-thin and flexible $\mathrm{Ti}_{3} \mathrm{C}_{2} \mathrm{~T}_{\mathrm{x}} /$ co-doped polyaniline electromagnetic interference shielding composite films Compos. Sci. Technol. 183107833 https:// doi.org/10.1016/j.compscitech.2019.107833

127. YH Zhan E Lago C Santillo AED Castillo S Hao 2020 An anisotropic layer-by-layer carbon nanotube/boron nitride/rubber composite and its application in electromagnetic shielding Nanoscale 1277827791 https://doi.org/10.1039/C9NR1 $0672 \mathrm{C}$

128. W Yang J-J Liu L-L Wang W Wang ACY Yuen 2020 Multifunctional MXene/natural rubber composite flms with exceptional flexibility and durability Compos. B Eng. 188107875 https://doi.org/10.1016/j.compositesb.2020.107875

129. X Jin J Wang L Dai X Liu L Li 2020 Flame-retardant poly(vinyl alcohol)/MXene multilayered films with outstanding electromagnetic interference shielding and thermal conductive performances Chem. Eng. J. 380122475 https://doi. org/10.1016/j.cej.2019.122475

130. W Ren H Zhu Y Yang Y Chen H Duan 2020 Flexible and robust silver coated non-woven fabric reinforced waterborne polyurethane flms for ultra-effcient electromagnetic shielding Compos. B Eng. 184107745 https://doi.org/10.1016/j.compo sitesb.2020.107745

131. YD Xu YQ Yang DX Yan HJ Duan GZ Zhao 2018 Gradient structure design of flexible waterborne polyurethane conductive films for ultraefficient electromagnetic shielding with low reflection characteristic ACS Appl. Mater. Interfaces 10 1914319152 https://doi.org/10.1021/acsami.8b05129

132. J Zhang N Kong S Uzun A Levitt S Seyedin 2020 Scalable manufacturing of free-standing, strong $\mathrm{Ti}_{3} \mathrm{C}_{2} \mathrm{~T}_{\mathrm{x}}$ MXene films with outstanding conductivity Adv. Mater. 322001093 https://doi.org/10.1002/adma.202001093 
133. L-C Jia C-G Zhou W-J Sun L Xu D-X Yan 2020 Water-based conductive ink for highly efficient electromagnetic interference shielding coating Chem. Eng. J. 384123368 https://doi. org/10.1016/j.cej.2019.123368

134. JB Xi YL Li EZ Zhou YJ Liu WW Gao 2018 Graphene aerogel films with expansion enhancement effect of highperformance electromagnetic interference shielding Carbon 1354451 https://doi.org/10.1016/j.carbon.2018.04.041

135. C Yuan J Huang Y Dong X Huang Y Lu 2020 Record-High transparent electromagnetic interference shielding achieved by simultaneous microwave fabry-perot interference and optical antireflection ACS Appl. Mater. Interfaces 1226659 26669 https://doi.org/10.1021/acsami.0c05334

136. L Chen J Zhao L Wang F Peng H Liu 2019 In-situ pyrolyzed polymethylsilsesquioxane multi-walled carbon nanotubes derived ceramic nanocomposites for electromagnetic wave absorption Ceram. Int. 451175611764 https://doi.org/10. 1016/j.ceramint.2019.03.052

137. HY Wang CG Ji C Zhang YL Zhang Z Zhang 2019 Highly transparent and broadband electromagnetic interference shielding based on ultrathin doped $\mathrm{Ag}$ and conducting oxides hybrid film structures ACS Appl. Mater. Interfaces 1111782 11791 https://doi.org/10.1021/acsami.9b00716

138. J Gu S Hu H Ji H Feng W Zhao 2020 Multi-layer silver nanowire/polyethylene terephthalate mesh structure for highly efficient transparent electromagnetic interference shielding Nanotechnology 31185303 https://doi.org/10.1088/ 1361-6528/ab6d9d

139. X Zhu J Xu F Qin Z Yan A Guo 2020 Highly efficient and stable transparent electromagnetic interference shielding films based on silver nanowires Nanoscale 121458914597 https://doi.org/10.1039/D0NR03790G

140. W Chen L-X Liu H-B Zhang Z-Z Yu 2020 Flexible, transparent, and conductive $\mathrm{Ti}_{3} \mathrm{C}_{2} \mathrm{~T}_{\mathrm{x}}$ MXene-Silver nanowire films with smart acoustic sensitivity for high-performance electromagnetic interference shielding ACS Nano 141664316653 https://doi.org/10.1021/acsnano.0c01635

141. Y Zhan X Hao L Wang X Jiang Y Cheng 2021 Superhydrophobic and flexible silver nanowire-coated cellulose filter papers with sputter-deposited nickel nanoparticles for ultrahigh electromagnetic interference shielding ACS Appl. Mater. Interfaces 131462314633 https://doi.org/10.1021/ acsami.1c03692

142. X-H Li X Li K-N Liao P Min T Liu 2016 Thermally annealed anisotropic graphene aerogels and their electrically conductive epoxy composites with excellent electromagnetic interference shielding efficiencies ACS Appl. Mater. Interfaces 8 3323033239 https://doi.org/10.1021/acsami.6b12295

143. Y Chen H-B Zhang Y Huang Y Jiang W-G Zheng 2015 Magnetic and electrically conductive epoxy/graphene/carbonyl iron nanocomposites for efficient electromagnetic interference shielding Compos. Sci. Technol. 118178185 https:// doi.org/10.1016/j.compscitech.2015.08.023

144. C Liang P Song H Qiu Y Zhang X Ma 2019 Constructing interconnected spherical hollow conductive networks in silver platelets/reduced graphene oxide foam/epoxy nanocomposites for superior electromagnetic interference shielding effectiveness Nanoscale 112259022598 https://doi.org/10. 1039/C9NR06022G

145. C Liang H Qiu Y Han H Gu P Song 2019 Superior electromagnetic interference shielding 3D graphene nanoplatelets/ reduced graphene oxide foam/epoxy nanocomposites with high thermal conductivity J. Mater. Chem. C 727252733 https://doi.org/10.1039/C8TC05955A

146. W Gao N Zhao T Yu J Xi A Mao 2020 High-efficiency electromagnetic interference shielding realized in nacre-mimetic graphene/polymer composite with extremely low graphene loading Carbon 157570577 https://doi.org/10.1016/j.carbon. 2019.10.051

147. H Fang $\mathrm{H}$ Guo Y Hu Y Ren P-C Hsu 2020 In-situ grown hollow $\mathrm{Fe}_{3} \mathrm{O}_{4}$ onto graphene foam nanocomposites with high EMI shielding effectiveness and thermal conductivity Compos. Sci. Technol. 188107975 https://doi.org/10.1016/j. compscitech.2019.107975

148. ZM Shen JC Feng 2019 Preparation of thermally conductive polymer composites with good electromagnetic interference shielding efficiency based on natural wood-derived carbon scaffolds ACS Sustain. Chem. Eng. 762596266 https://doi. org/10.1021/acssuschemeng.8b06661

149. Y Huangfu C Liang Y Han H Qiu P Song 2019 Fabrication and investigation on the $\mathrm{Fe}_{3} \mathrm{O}_{4}$ /thermally annealed graphene aerogel/epoxy electromagnetic interference shielding nanocomposites Compos. Sci. Technol. 1697075 https://doi.org/ 10.1016/j.compscitech.2018.11.012

150. L Wang P Song C-T Lin J Kong J Gu 2020 3D shapeable, superior electrically conductive cellulose nanofibers $/ \mathrm{Ti}_{3} \mathrm{C}_{2} \mathrm{~T}_{\mathrm{x}}$ MXene aerogels/epoxy nanocomposites for promising EMI shielding Research 20204093732 https://doi.org/10.34133/ 2020/4093732

151. Y Huangfu K Ruan H Qiu Y Lu C Liang 2019 Fabrication and investigation on the PANI/MWCNT/thermally annealed graphene aerogel/epoxy electromagnetic interference shielding nanocomposites Compos. A Appl. S. 121265272 https:// doi.org/10.1016/j.compositesa.2019.03.041

152. P Song C Liang L Wang H Qiu H Gu 2019 Obviously improved electromagnetic interference shielding performances for epoxy composites via constructing honeycomb structural reduced graphene oxide Compos. Sci. Technol. 181 107698 https://doi.org/10.1016/j.compscitech.2019.107698 